\title{
A PMSM Driven Electric Scooter System with a V-Belt Continuously Variable Transmission Using a Novel Hybrid Modified Recurrent Legendre Neural Network Control
}

\author{
Chih-Hong $\operatorname{Lin}^{\dagger}$ \\ ${ }^{\dagger}$ Department of Electrical Engineering, National United University, Miaoli, Taiwan
}

\begin{abstract}
An electric scooter with a V-belt continuously variable transmission (CVT) driven by a permanent magnet synchronous motor (PMSM) has a lot of nonlinear and time-varying characteristics, and accurate dynamic models are difficult to establish for linear controller designs. A PMSM servo-drive electric scooter controlled by a novel hybrid modified recurrent Legendre neural network (NN) control system is proposed to solve difficulties of linear controllers under the occurrence of nonlinear load disturbances and parameters variations. Firstly, the system structure of a V-belt CVT driven electric scooter using a PMSM servo drive is established. Secondly, the novel hybrid modified recurrent Legendre NN control system, which consists of an inspector control, a modified recurrent Legendre NN control with an adaptation law, and a recouped control with an estimation law, is proposed to improve its performance. Moreover, the on-line parameter tuning method of the modified recurrent Legendre NN is derived according to the Lyapunov stability theorem and the gradient descent method. Furthermore, two optimal learning rates for the modified recurrent Legendre NN are derived to speed up the parameter convergence. Finally, comparative studies are carried out to show the effectiveness of the proposed control scheme through experimental results.
\end{abstract}

Key words: Electric scooter, Lyapunov stability, Modified recurrent Legendre neural network, Permanent magnet synchronous motor, V-belt continuously variable transmission

\section{INTRODUCTION}

There are many countries trying to develop electric vehicles in order to reduce both their dependence on petroleum and the effects of air pollution. Scooters are popular for personal transportation. This is partly due to the fact that they are cheap to buy and operate and convenient to park and store. Because scooters are easier and cheaper to own than cars in most parts of the world, the development of control methods is one of the good research areas for electric scooters. Electric scooters are driven by $\mathrm{AC}$ motors, so the selection of the $\mathrm{AC}$ motors drive systems is important. There are several basic types of $\mathrm{AC}$

Manuscript received Mar. 28, 2014; accepted Jun.10, 2014

Recommended for publication by Associate Editor Shihua Li.

†CorrespondingAuthor:jhlin@nuu.edu.tw

Tel:+886-3-7381349,Fax:+886-3-7327887, National United University

Dept. of Electrical Eng., National United University, Taiwan servo motors such as PMSMs, switched reluctance motors (SRMs) and induction motors (IMs). PMSMs provide higher efficiency, higher power density, and lower power loss for their size when compared to SRMs and IMs. Direct torque control (DTC) [1]-[4] and field-oriented control [5]-[7] are the two most popular control techniques used with PMSMs. The classical DTC [3], [4] has some drawbacks. One of these drawbacks is the higher torque ripple and high current ripple generated in steady state operation when compared to the field-oriented control system. On the other hand, the field-oriented control is much less sensitive to parameter variations and has faster operation in the four quadrants [5]-[7]. Hence, field-oriented control is used to reduce the torque ripple influence in this paper.

Artificial neural networks (ANNs) have become a formidable learning skill for performing many complex tasks such as highly nonlinear approximations [8], [9] and the control of dynamical systems [10], [11]. One of the major 
drawbacks of NNs is that they are computationally intensive and need a large number of iterations for their training. In order to reduce the computational complexity, a functional-link $\mathrm{NN}$, which has shown that it is capable of producing performance that is similar to that of NNs but with a much lower computational cost, was introduced in [12], [13]. Moreover, a functional-link NN-based nonlinear dynamic system identification with satisfactory results was reported in [14]. It is shown that the performance of the functional-link NN is similar to that of a NN but with a faster convergence and less computational complexity. Moreover, a comprehensive survey on various applications for functional-link NNs has been presented in [15].The functional-link $\mathrm{NN}$ has emerged as a powerful learning technique for both nonlinear approximations and the dynamic control of systems. A novel Legendre polynomial based linear NN for static function approximation was proposed by Yang et al. [16]. It was demonstrated that this network has a fast convergence, and provide high accuracy. Recently, Legendre polynomial NNs for channel equalization problems have been proposed in [17], [18]. The superior performance of this Legendre NN equalizer over the NN-based and RBF-based equalizers for different nonlinear channel models has been demonstrated. Moreover, the computational complexity of the Legendre NNs is lower than that of the functional-link $\mathrm{NN}$ since the evaluation of Legendre polynomials involves less computation than the evaluation of trigonometric functions [19]. In addition, the predictive approach is based on a Legendre neural network and a random time strength function via a promising data mining technique used in machine learning and proposed in [20]. Furthermore, a computationally efficient Legendre NN for nonlinear active noise cancellation was shown in [21]. However, the proposed Legendre NN is only a single layer network structure without a feedback loop. It cannot adequately approximate dynamic behaviors found in PMSM servo-driven electric scooter systems with nonlinear and time-varying characteristics.

The recurrent NN has received an increasing amount of attention due to its structural advantage in the modeling of nonlinear systems and the dynamic control of these systems [22]-[26]. These networks are capable of effective identification and control of complex process dynamics but at the expense of increased computational complexity. The typical Elman NN, which is a partial recurrent network model that was first proposed by Elman [27], has one hidden layer with a delayed feedback. The Elman $\mathrm{NN}$ is capable of providing standard state-space representation for dynamic systems. In order to improve the ability for identifying high order systems, some recurrent modified Elman NNs [28]-[30] have been proposed recently. They have been shown to have more advantages than the basic Elman NN, including good performance, high accuracy, dynamic robustness and fast transient performance. However, the parameters of these recurrent modified Elman NNs [28]-[30] have a slower convergence speed due to their higher computational complexity and complex network structure. Additionally, the recurrent wavelet NNs proposed by [31]-[33], which combine the properties of the attractor dynamics of the recurrent $\mathrm{NN}$ and the good convergence performance of the wavelet $\mathrm{NN}$, can reduce the computational complexity. However, they also have slower convergence speeds due to the adopted fixed learning rates for the parameters in these recurrent wavelet NNs. Therefore, in order to reduce the network complexity and speed-up the convergence, the novel simpler $\mathrm{NN}$ structure of modified recurrent Legendre $\mathrm{NN}$, which has a self-feedback connection in the hidden layer and a recurrent connection between the output layer and the input layer, is more powerful than the three-layer recurrent NNs for dealing with time-varying and nonlinear dynamic systems. Two optimal learning rates for the parameters in the modified recurrent Legendre $\mathrm{NN}$ are proposed to enhance the convergence speed in this paper.

In electric scooters [34]-[37] with nonlinear uncertainties, the hybrid recurrent fuzzy $\mathrm{NN}$ controller may not provide satisfactory control performance when operated over a wide range of operating conditions. In [34], a hybrid recurrent fuzzy NN controller using a rotor flux estimator was used to control the PMSM without a shaft encoder to drive electric scooter. In [35] a hybrid recurrent fuzzy NN control was used for the feedback control of PMSM driven electric scooters with a shaft encoder. A favorable speed tracking responses can only be achieved by using a hybrid recurrent fuzzy NN controller at $1200 \mathrm{rpm}$ in the nominal case and in the parameter variation case. However, poor speed tracking responses are encountered at $2400 \mathrm{rpm}$ due to uncertain perturbations. On the other hand, if the controlled plant has a highly nonlinear uncertainty, the linear controller may not provide satisfactory control performance. Thus, to ensure the control performance and robustness, a V-belt CVT driven electric scooter using a PMSM servo drive is controlled by the novel hybrid modified recurrent Legendre NN control system developed in this paper. The novel hybrid modified recurrent Legendre NN control system, which is composed of an inspector control, a modified recurrent Legendre NN control with an adaptation law and a recouped control with an estimation law, is applied to a V-belt CVT driven electric scooter by using the PMSM servo drive system. The novel hybrid modified recurrent Legendre NN control system has a fast convergence ability and good generalization capability. In addition, the adaptation law of the on-line parameters in the modified recurrent Legendre $\mathrm{NN}$ and the estimation law of the recouped controller can be derived according to the Lyapunov stability theorem and the gradient descent method. Furthermore, two optimal learning rates for the modified recurrent Legendre $\mathrm{NN}$ are proposed to enhance the 
convergence speed. The control method, which is not dependent upon the predetermined characteristics of the system, can adapt to any change in the system characteristics. Finally, the control performance of the proposed novel hybrid modified recurrent Legendre $\mathrm{NN}$ control system is verified by experimental results.

This paper is organized as follows. The system structure of a V-belt CVT driven electric scooter using a PMSM servo drive system is reviewed in Section II. The design method of the novel hybrid modified recurrent Legendre NN control system is presented in Section III. Experimental results are illustrated in Section IV. Some conclusions are given in Section V.

\section{STRUCTURE OF A V-BELT CVT DRIVEN ELECTRIC SCOOTER SYSTEM USING A PMSM SERVO DRIVE}

Due to electric scooter systems with unknown nonlinear uncertainties, i.e., load torque, rolling resistance, wind resistance and braking force, the V-belt CVTs and clutches in scooters can be categorized as functioning in one of two operating modes depending on the speed of the V-belt CVT output axis: disengaged or completely coupled. At the start of the PMSM drive cycles, the scooter is in an idle state. The clutch is initially disengaged, and subsequent transitions between the modes are controlled by the clutch axis rotational speed. Except for the mechanical losses, the PMSM power is transmitted through the V-belt CVT and clutch to the wheel in an electric scooter. For the sake of a convenient design, the stator voltage equations of a V-belt CVT driven electric scooter using a PMSM servo drive in the synchronously rotating reference frame can be described as follows [5]-[7]:

$$
\begin{gathered}
v_{q r}=R_{r} i_{q r}+L_{q r} \dot{i}_{q r}+\omega_{f}\left(L_{d r} i_{d r}+\lambda_{f d}\right) \\
v_{d r}=R_{r} i_{d r}+L_{d r} \dot{i}_{d r}-\omega_{f} L_{q r} i_{q r}
\end{gathered}
$$

where $v_{q r}$ and $v_{d r}$ are the $d$-axis and $q$-axis stator voltages, $i_{q r}$ and $i_{d r}$ are the $d$-axis and $q$-axis stator currents, $L_{q r}$ and $L_{d r}$ are the $d$-axis and $q$-axis stator inductances, $\lambda_{f d}$ is the $d$-axis permanent magnet flux linkage, $R_{r}$ is the stator resistance, and $\omega_{f}$ is the electrical angular speed.

The electromagnetic torque $T_{e}$ of a V-belt CVT driven electric scooter using a PMSM servo drive can be described as:

$$
T_{e}=3 P_{r}\left[\lambda_{f d} i_{q r}+\left(L_{d r}-L_{q r}\right) i_{d r} i_{q r}\right] / 4
$$

where $P_{r}$ is the number of poles. Then, the dynamic equation of a V-belt CVT driven electric scooter using a PMSM servo drive [34-37] can be represented as:

$$
J_{r} \dot{\omega}_{r}+B_{r} \omega_{r}+T_{l}\left(T_{a}, \Delta T_{p}, F_{l}\left(B_{g}\right), v_{a}\left(v_{r}, B_{g}\right), \tau_{a}\left(v_{r}\right), \omega_{r}^{2}\right)=T_{e}
$$

where $T_{l}\left(T_{a}, \Delta T_{p}, F_{l}\left(B_{g}\right), v_{a}\left(v_{r}, B_{g}\right), \tau_{a}\left(v_{r}\right), \omega_{r}^{2}\right)=T_{a}+\Delta T_{p}+T_{u n}$ [36], [37] represents the lumped nonlinear external disturbances and parameter variations, (e.g. the electric scooter system including the fixed load torque $T_{a}$, the variation of the parameters $\Delta T_{p}$, the rolling resistance $v_{a}\left(v_{r}, B_{g}\right)$, the wind resistance $\tau_{a}\left(v_{r}\right)$ and the braking force $\left.F_{l}\left(B_{g}\right)\right), \Delta T_{p}=\Delta J_{r} \dot{\omega}_{r}+\Delta B_{r} \omega_{r}$ represents the variation of the parameters, $T_{u n}=F_{l}\left(B_{g}\right)+v_{a}\left(v_{r}, B_{g}\right)+\tau_{a}\left(v_{r}\right) \omega_{r}^{2}$ represents the unknown nonlinear load torque, $v_{r}$ is the total wind velocity, $B_{g}$ is the total frictional coefficient of the ground surface, $B_{r}$ is the total viscous frictional coefficient, and $J_{r}$ is the total moment of inertia including the electric scooter itself. $\omega_{r}=2 \omega_{f} / P_{r}$ is the rotor speed. Due to $L_{d r}=L_{q r}$, for a surface-mounted PMSM, the second term of (3) is zero. Moreover, $\lambda_{f d}$ is a constant for the surface-mounted PMSM. The rotor flux is produced in the $d$-axis only, while the current vector is generated in the $q$-axis for the field-oriented control. When the $d$-axis rotor flux is a constant and the torque angle is $\pi / 2$ [6-7], the maximum torque per ampere can be reached for the field-oriented control. The electromagnetic torque $T_{e}$ is linearly proportional to the $q$-axis current $i_{q r}$, which is determined by the closed-loop control. The control principle of the PMSM servo-drive system is based on the field orientation. A V-belt CVT driven electric scooter using a PMSM servo drive system with the implementation of field-oriented control can be reduced as:

$$
T_{e}=k_{r} i_{q r}^{*}
$$

in which $k_{r}=3 P_{r} \lambda_{f d} / 4$ is the torque constant. A block diagram of a V-belt CVT driven electric scooter using a PMSM servo drive system is shown in Fig. 1.

The whole system of a V-belt CVT driven electric scooter using a PMSM servo drive can be indicated as follows: a field-oriented institution, a PI current loop control, one set of sinusoidal pulse-width-modulation (PWM) control circuits, one set of interlock and isolated circuits, a voltage source inverter with three sets of insulated-gate bipolar transistor (IGBT) power modules, and a speed controller [33]-[35]. The PI current loop controller is a current loop tracking controller. In order to attain a good dynamic response, all of the gains for a well-known PI current loop controller are listed as follows: $k_{p c}=9.5$ and $k_{i c}=k_{p c} / T_{i c}=2.8$ through some heuristic knowledge [38]-[40] of the tuning of the PI controller. The field-oriented institution consists of a coordinate transformation, $\sin \theta_{f} / \cos \theta_{f}$ generation and 
lookup table generation. A TMS320C32 digital signal processor (DSP) control system is used to implement the field-oriented institution control and speed control. A V-belt CVT driven electric scooter using a PMSM servo drive is manipulated under the lumped nonlinear external disturbances

$$
T_{l}\left(T_{a}, \Delta T_{p}, F_{l}\left(B_{g}\right), v_{a}\left(v_{r}, B_{g}\right), \tau_{a}\left(v_{r}\right), \omega_{r}^{2}\right)=T_{a}+\Delta T_{p}+T_{u n} .
$$

\section{Design OF THE CONTROL SyStem}

The nonlinear uncertainties of a V-belt CVT driven electric scooter using a PMSM servo drive such as the nonlinear friction force of the transmission belt and clutch, rolling resistance, wind resistance and braking force, lead to degenerate tracking responses in the command current and speed. These nonlinear uncertainties cause variations in the rotor inertia and friction. For a convenient novel hybrid modified recurrent Legendre NN design, the dynamic equation of the V-belt CVT driven electric scooter using the PMSM servo drive from (4) can be rewritten as:

$$
\begin{aligned}
\dot{\omega}_{r} & =-T_{l}\left(T_{a}, \Delta T_{p}, F_{l}\left(B_{g}\right), v_{a}\left(v_{r}, B_{g}\right), \tau_{a}\left(v_{r}\right), \omega_{r}^{2}\right) / J_{r} \\
& -B_{r} \omega_{r} / J_{r}+k_{r} i_{q r}^{*} / J_{r} \\
& =C_{a} T_{l}\left(T_{a}, \Delta T_{p}, F_{l}\left(B_{g}\right), v_{a}\left(v_{r}, B_{g}\right), \tau_{a}\left(v_{r}\right), \omega_{r}^{2}\right)+A_{a} \omega_{r}+B_{a} u_{n}(6)
\end{aligned}
$$

where $u_{n}=i_{q r}^{*}$ is the command current of the stator of the PMSM. $A_{a}=-B_{r} / J_{r}, B_{a}=k_{r} / J_{r}$ and $C_{a}=-1 / J_{r}$ are three known constants. When uncertainties including the lumped nonlinear external disturbances occur, the parameters are assumed to be bounded, i.e., $\left|A_{a} \omega_{r}\right| \leq D_{1}\left(\omega_{r}\right), \quad\left|C_{a} T_{l}\left(T_{a}, \Delta T_{p}, F_{l}\left(B_{g}\right), v_{a}\left(v_{r}, B_{g}\right), \tau_{a}\left(v_{r}\right), \omega_{r}^{2}\right)\right| \leq D_{2}$, and $D_{3} \leq B_{a}$, where $D_{1}\left(\omega_{r}\right)$ is a known continuous function, and $D_{2}$ and $D_{3}$ are two known constants. Then, the tracking error can be defined as:

$$
e=\omega^{*}-\omega_{r}
$$

where $\omega^{*}$ represents the desired command rotor speed, and $e$ is the tracking error between the desired rotor speed and the actual rotor speed. If all of the parameters of the V-belt CVT driven electric scooter using the PMSM servo drive system including the lumped nonlinear external disturbances and parameter variations are well known, the ideal control law can be designed as:

$$
\begin{aligned}
u_{n}^{*}= & {\left[-C_{a} T_{l}\left(T_{a}, \Delta T_{p}, F_{l}\left(B_{g}\right), v_{a}\left(v_{r}, B_{g}\right), \tau_{a}\left(v_{r}\right), \omega_{r}^{2}\right)\right] / B_{a} } \\
& +\left[\dot{\omega}^{*}+k_{1} e-A_{a} \omega_{r}\right] / B_{a}
\end{aligned}
$$

in which $k_{1}$ is a positive constant. Substituting (8) into (6), the error dynamic equation can be obtained as:

$$
\dot{e}+k_{1} e=0
$$

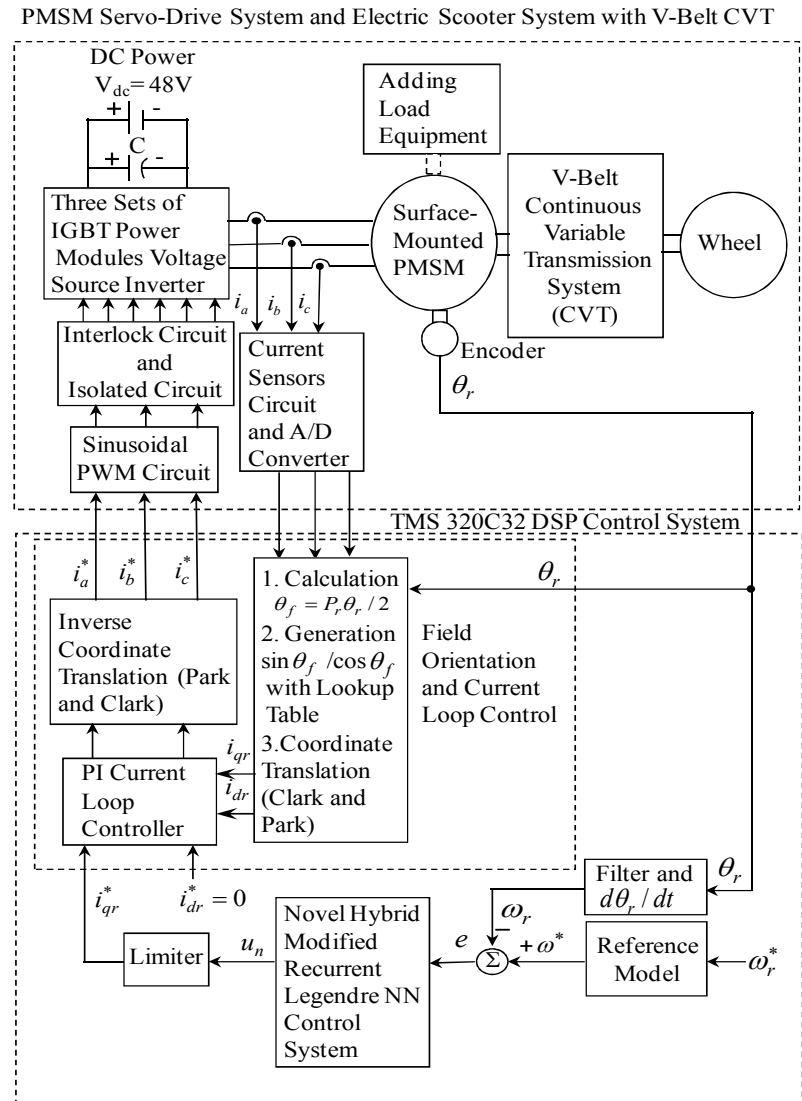

Fig. 1. Block diagram of a V-belt CVT driven electric scooter using a PMSM servo drive.

The system state can track the desired trajectory gradually if $e(t) \rightarrow 0$ as $t \rightarrow \infty$ in (9). However, a novel hybrid modified recurrent Legendre NN control system is proposed to control the V-belt CVT driven electric scooter using the PMSM servo drive under uncertain perturbations.

\section{A. Novel Hybrid Modified Recurrent Legendre NN Control}

The configuration of the proposed novel hybrid modified recurrent Legendre NN control system, which is composed of an inspector control system, a modified recurrent Legendre NN controller and a recouped controller, is described in Fig. 2.

The control law is designed as:

$$
u_{n}=u_{i n}+u_{r c}+u_{r e}
$$

where $u_{i n}$ is the proposed inspector control that is capable of stabilizing around a predetermined bound area in the states of the controlled system. The modified recurrent Legendre $\mathrm{NN}$ control $u_{r c}$ is a major tracking controller, which is used to imitate an ideal control law. The recouped control $u_{r e}$ is designed to recoup the difference between the ideal control law and the modified recurrent Legendre NN control. Since 


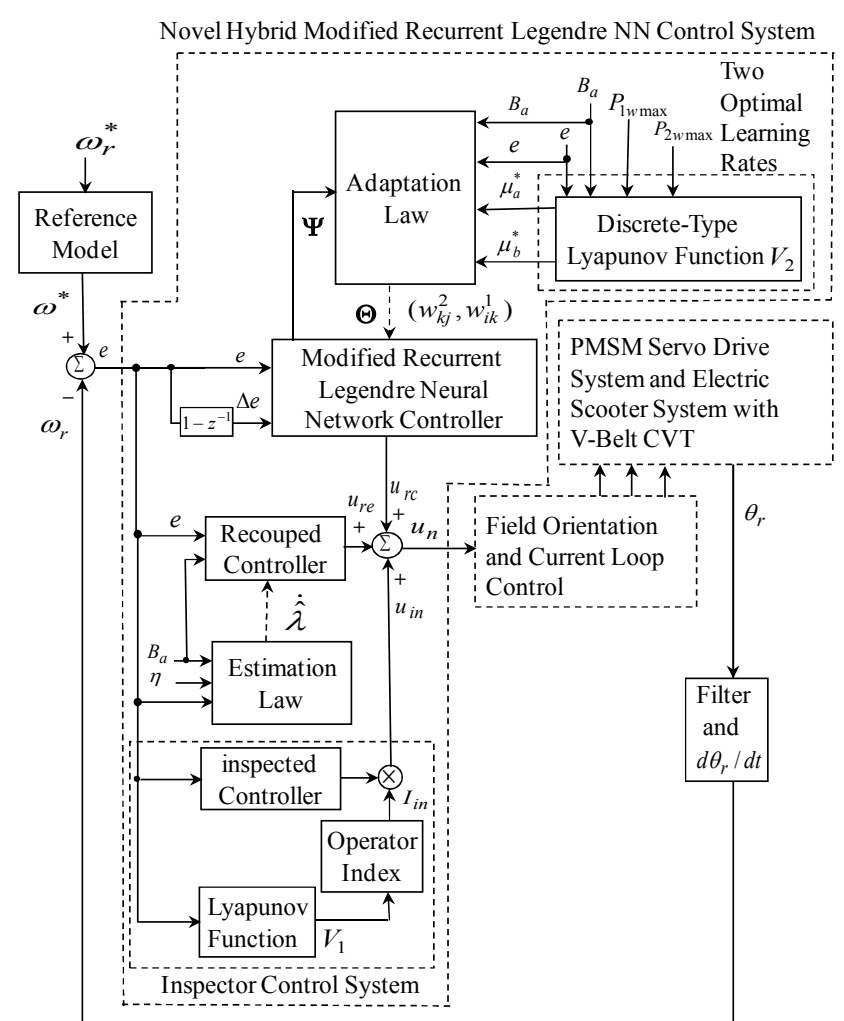

Fig. 2. Block diagram of the novel hybrid modified recurrent Legendre NN control system.

the inspector control caused an overdone and chattering effort, the modified recurrent Legendre NN control and the recouped control are proposed to reduce and smooth the control effort when the system states are inside a predetermined bound area. When the modified recurrent Legendre NN approximation properties cannot be ensured, the inspector control is able to take action. For the condition of the divergence of states, the design of the novel hybrid modified recurrent Legendre NN control system is essential to stretch the divergent states back to the predestinated bound area. The novel hybrid modified recurrent Legendre $\mathrm{NN}$ control system can uniformly approximate the ideal control law inside the bound area. Then the stability of the system can be warranted. Error dynamic equations from (6) to (10) can be acquired as:

$$
\dot{e}=-k_{1} e+\left[u_{n}^{*}-u_{i n}-u_{r c}-u_{r e}\right] B_{a}
$$

Firstly, the inspected control $u_{\text {in }}$ can be designed as:

$$
u_{\text {in }}=I_{\text {in }} \operatorname{sgn}\left(e B_{a}\right)\left[D_{1}\left(\omega_{r}\right)+D_{2}+\left|\dot{\omega}^{*}\right|+\left|k_{1} e\right|\right] / B_{a}
$$

in which $\operatorname{sgn}(\cdot)$ is a sign function. When the modified recurrent Legendre $\mathrm{NN}$ approximation properties cannot be ensured, the inspector control law is able to take action, i.e., $I_{i n}=1$. Due to inadequate bound values, e.g., $D_{1}\left(\omega_{r}\right), D_{2}$, $D_{3}$ and the sign function, the inspected control can produce an overdone and chattering effort. However, the modified recurrent Legendre NN control and the recouped control can

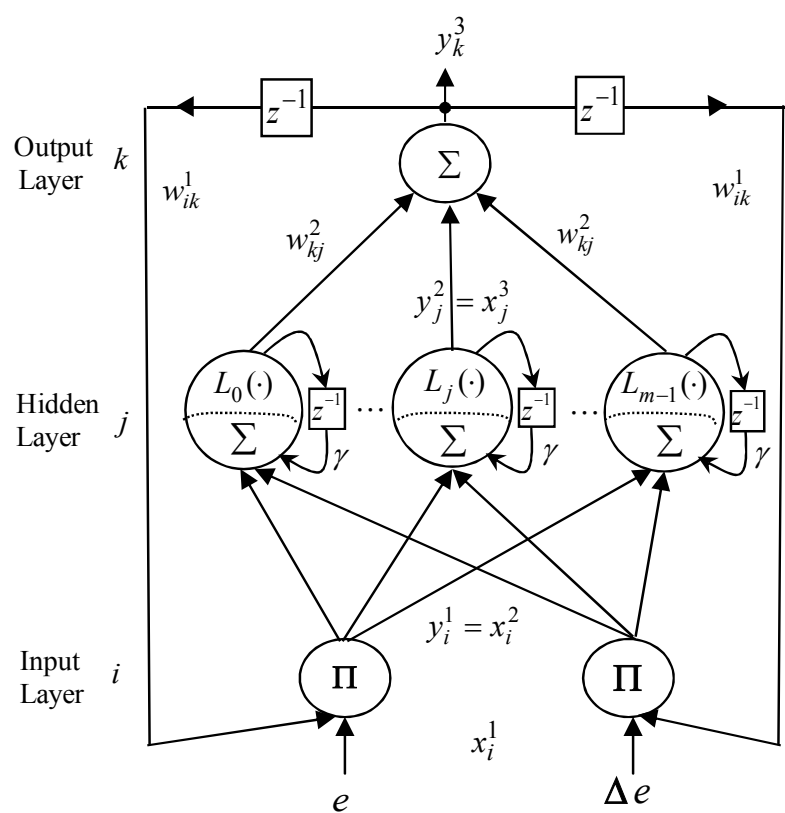

Fig. 3. Structure of the three-layer modified recurrent Legendre NN.

be devised to eliminate this flaw. The modified recurrent Legendre $\mathrm{NN}$ control is raised to imitate an ideal control $u_{n}^{*}$. Then the recouped control is posed to recoup the difference between the ideal control $u_{n}^{*}$ and the modified recurrent Legendre NN control $u_{r c}$.

\section{B. Modified Recurrent Legendre NN}

The architecture of the proposed three-layer modified recurrent Legendre $\mathrm{NN}$ is depicted in Fig. 3. It is composed of an input layer, a hidden layer and an output layer. The activation functions and signal actions of the nodes in each layer of the modified recurrent Legendre $\mathrm{NN}$ can be described as follows:

1) First layer - input layer: Each node in this layer is indicated by using $\Pi$, which multiplies all of the input signals by one another. The output signals are the results of the product. The inputs and outputs for each node $i$ in this layer can be expressed as:

$$
\operatorname{nod}_{i}^{1}=\prod_{k} x_{i}^{1}(N) w_{i k}^{1} y_{k}^{3}(N-1), y_{i}^{1}=f_{i}^{1}\left(\operatorname{nod}_{i}^{1}\right)=\operatorname{nod}_{i}^{1}, \quad i=1,2(13)
$$

$x_{1}^{1}=\omega^{*}-\omega_{r}=e$ is the tracking error between the desired speed $\omega^{*}$ and the rotor speed $\omega_{r} \cdot x_{2}^{1}=e\left(1-z^{-1}\right)=\Delta e$ is the tracking error change. $w_{i k}^{1}$ is the recurrent weight between the output layer and the input layer. $N$ denotes the number of iterations. $y_{k}^{3}$ is the output value of the output layer in the modified recurrent Legendre NN.

2) Second layer - hidden layer: The single node $j$ th in this layer is labeled with $\Sigma$. The net input and the net output for 
node $j$ th of this layer are expressed as:

$$
\begin{gathered}
\operatorname{nod}_{j}^{2}(N)=\sum_{i=1}^{2} y_{i}^{1}(N)+\gamma y_{j}^{2}(N-1), \\
y_{j}^{2}=f_{j}^{2}\left(L_{j}\left(\operatorname{nod}_{j}^{2}\right)\right), j=0,1, \cdots, m-1
\end{gathered}
$$

Legendre polynomials [17]-[19] are selected for the activation function of the hidden layer. The Legendre polynomials are denoted by $L_{n}(x)$, where $n$ is the order of expansion, $-1<x<1$ is the argument of the polynomial, $m$ is the number of nodes, and $\gamma$ is the self-connecting feedback gain of the hidden layer which is selected to be between 0 and 1. The zero, the first and the second order Legendre polynomials are given by $L_{0}(x)=1, L_{1}(x)=x$ and $L_{2}(x)=\left(3 x^{2}-1\right) / 2, \quad$ respectively. The higher order polynomials are given by $L_{3}(x)=\left(5 x^{3}-3 x\right) / 2$ and $L_{4}(x)=\left(35 x^{4}-30 x^{2}+3\right) / 8$. The higher order Legendre polynomials are generated by the recursive formula given by: $L_{n+1}(x)=\left[(2 n+1) x L_{n}(x)-n L_{n-1}(x)\right] /(n+1)$.

3) Third layer - output layer: The single node $k$ th in this layer is labeled with $\sum$. It computes the overall output as a summation of all of the input signals. The net input and the net output for node $k$ th in this layer are expressed as:

$$
\operatorname{nod}_{k}^{3}=\sum_{j=0}^{m-1} w_{k j}^{2} y_{j}^{2}(N), y_{k}^{3}=f_{k}^{3}\left(\operatorname{nod}_{k}^{3}\right)=\operatorname{nod}_{k}^{3}, \quad k=1
$$

where $w_{k j}^{2}$ is the connective weight between the hidden layer and the output layer; $f_{k}^{3}$ is the activation function, which is selected as a linear function; and $x_{j}^{3}(N)=y_{j}^{2}(N)$ represents the $j$ th input to the node of the output layer. The output value of the modified recurrent Legendre NN can be represented as $y_{k}^{3}(N)=u_{r c}$. Then the output value of the modified recurrent Legendre NN, $u_{r c}$, can be denoted as:

$$
u_{r c}=\Theta^{T} \Psi
$$

in which $\Theta=\left[\begin{array}{lll}w_{10}^{1} & \cdots & w_{1, m-1}^{1}\end{array}\right]^{T}$ is the adjustable weight parameter vector between the hidden layer and the output layer of the recurrent Legendre NN. $\Psi=\left[\begin{array}{lll}x_{0}^{3} & \cdots & x_{m-1}^{3}\end{array}\right]^{T}$ is the input vector in the output layer of the modified recurrent Legendre $\mathrm{NN}$, in which $x_{j}^{3}$ is determined by the selected Legendre polynomials.

\section{Recouped Control with Estimation Law}

By assuming that the sampling frequency is sufficiently high and that the back-EMF is constant during a sampling period, the recouped control with estimation law of a PMSM are given as follows: In order to evolve the recouped control $u_{r e}$, the minimum approximation error $\delta$ is defined as:

$$
\delta=u_{n}^{*}-u_{r c}^{*}=u_{n}^{*}-\left(\Theta^{*}\right)^{T} \Psi
$$

in which $\Theta^{*}$ is an ideal weight vector to reach the minimum approximation error. It is assumed that the absolute value of $\delta$ is less than a small positive value $\lambda$, i.e., $|\delta|<\lambda$. Then, the error dynamic equation from (11) can be rewritten as:

$$
\begin{aligned}
& \dot{e}=-k_{1} e+\left[\left(u_{n}^{*}-u_{r c}\right)-u_{r e}-u_{i n}\right] B_{a} \\
& =-k_{1} e+\left[\left(u_{n}^{*}-u_{r c}^{*}+u_{r c}^{*}-u_{r c}\right)-u_{r e}-u_{i n}\right] B_{a} \\
& \left.=-k_{1} e+\left[\left(u_{n}^{*}-u_{r c}^{*}\right)+\left(\Theta^{*}\right)^{T} \Psi-(\Theta)^{T} \Psi\right)-u_{r e}-u_{i n}\right] B_{a} \\
& \quad=-k_{1} e+\left[\delta+\left(\Theta^{*}-\Theta\right)^{T} \Psi-u_{r e}-u_{i n}\right] B_{a}
\end{aligned}
$$

Then, the Lyapunov function is selected as:

$$
V_{1}(t)=e^{2} / 2+\left(\Theta^{*}-\Theta\right)^{T}\left(\Theta^{*}-\Theta\right) /\left(2 \mu_{a}\right)+\tilde{\lambda}^{2} /(2 \eta)
$$

in which $\tilde{\lambda}=\hat{\lambda}-\lambda$ is the bound estimated error, $\mu_{a}>0$ is the learning rate, and $\eta$ is the adaptation gain. By differentiating the Lyapunov function with respect to $t$ and using (18), (19) can be rewritten as:

$$
\begin{aligned}
\dot{V}_{1}(t)= & \dot{e} e-\left(\Theta^{*}-\Theta\right)^{T} \dot{\Theta} / \mu_{a}+\tilde{\lambda} \dot{\hat{\lambda}} / \eta \\
= & \left\{-k_{1} e+\left[\delta-u_{r e}-u_{i n}\right] B_{a} e\right. \\
& +\left(\Theta^{*}-\Theta\right)^{T} \Psi B_{a} e-\left(\Theta^{*}-\Theta\right)^{T} \dot{\Theta} / \mu_{a}+\tilde{\lambda} \dot{\hat{\lambda}} / \eta
\end{aligned}
$$

To satisfy $\dot{V}_{1} \leq 0$, the adaptation law $\dot{\Theta}$ and the recouped controller $u_{r e}$ with the estimation law $\dot{\hat{\lambda}}$ can be designed as follows:

$$
\begin{gathered}
\dot{\Theta}=\mu_{a} \Psi B_{a} e \\
u_{r e}=\hat{\lambda} \operatorname{sgn}\left(B_{a} e\right) \\
\dot{\hat{\lambda}}=\eta\left|B_{a} e\right|
\end{gathered}
$$

By substituting (12), (21) and (22) into (20) and using (12) with $I_{\text {in }}=0,(20)$ can be represented as:

$$
\dot{V}_{1}(t)=-k_{1} e^{2}+\left(\delta-\hat{\lambda} \operatorname{sgn}\left(B_{a} e\right)\right) B_{a} e+\tilde{\lambda} \dot{\hat{\lambda}} / \eta
$$

By substituting (23) into (24), (24) can be obtained as:

$$
\dot{V}_{1}(t) \leq-k_{1} e^{2}+\{|\delta|-\lambda\}\left|B_{a} e\right| \leq-k_{1} e^{2} \quad \leq 0
$$

From (25), $\dot{V}_{1}(t)$ is a negative semi-definite value, i.e. $V_{1}(t) \leq V_{1}(0)$. This implies that $e$ and $\left(\Theta^{*}-\Theta\right)$ are bounded. For proof that the hybrid modified recurrent Legendre NN control system can gradually become stable, the function is defined as:

$$
\varepsilon(t)=-\dot{V}_{1}(t)=k_{1} e^{2}
$$

Integrating (26) with respect to $t$ results in:

$$
\int_{0}^{t} \varepsilon(\tau) d \tau=\int_{0}^{t}\left[-\dot{V}_{1}(t)\right] d t=V_{1}(0)-V_{1}(t)
$$

Since $V_{1}(0)$ is bounded, and $V_{1}(t)$ is non-increasing and bounded:

$$
\lim _{t \rightarrow \infty} \int_{0}^{t} \varepsilon(\tau) d \tau<\infty
$$

Differentiating (26) with respect to $t$ gives: 


$$
\dot{\varepsilon}(t)=2 k_{1} e \dot{e}
$$

All of the variables in the right side of (18) are bounded. This implies that $\dot{e}$ is also bounded. Then, $\varepsilon(t)$ is a uniformly continuous function [41-42]. It is denoted that $\lim _{t \rightarrow \infty} \varepsilon(t)=0$ by using Barbalat's lemma [41-42]. Therefore $e(t) \rightarrow 0$ as $t \rightarrow \infty$. From the above proof, the novel hybrid modified recurrent Legendre $\mathrm{NN}$ control system becomes gradually stable. Moreover, the tracking error $e(t)$ of the system will converge to zero. Furthermore, in order to avoid the chattering phenomenon of recouped controller $u_{r e}$, the sign the function $\operatorname{sgn}\left(B_{a} e\right)$ can be replaced by the equation $B_{a} e /\left(\left|B_{a} e\right|+\rho\right)$, where $\rho=\left\{\begin{array}{c}\rho_{0},\left|B_{a} e\right|<\tau \\ 0,\left|B_{a} e\right| \geq \tau\end{array}\right.$, in which $\rho_{0}$ and $\tau$ are positive constants.

\section{Parameter Tuning Methodology and Convergence Analysis}

According to the Lyapunov stability theorem and the gradient descent method, an on-line parameters training methodology for the modified recurrent Legendre NN can be derived and trained effectively. Then the parameter of adaptation law $\dot{\Theta}$ shown in (21) can be computed by the gradient descent method for the proper choice of two learning rates. The parameter convergence can be guaranteed but the convergent speed is reduced due to a smaller value for the learning rate. On the other hand, the parameter convergence may have an oscillation due to a larger value for the learning rate. In order to train the modified recurrent Legendre NN efficiently, two optimal learning rates will be derived to achieve a fast convergence of the output tracking error. The adaptation law $\dot{\Theta}$ shown in (21) can be rewritten as:

$$
\dot{w}_{k j}^{2}=\mu_{a} \Psi B_{a} e
$$

To train the parameters of the modified recurrent Legendre NN effectively, the method to obtain a recursively gradient vector is very important. Each component can be defined as a derivative of the cost function in the training algorithm. The gradient vector is calculated in the direction opposite the flow of the output of each node. This is done by means of the chain rule. In order to describe the on-line training algorithm of the modified recurrent Legendre $\mathrm{NN}$, a cost function is defined as [43]:

$$
V_{2}=e^{2} / 2
$$

The adaptation law of the connective weight by means of the gradient descent method can be represented as:

$$
\dot{w}_{k j}^{2}=-\mu_{a} \frac{\partial V_{2}}{\partial w_{k j}^{2}}=-\mu_{a} \frac{\partial V_{2}}{\partial y_{k}^{3}} \frac{\partial y_{k}^{3}}{\partial n o d_{k}^{3}} \frac{\partial n o d_{k}^{3}}{\partial w_{k j}^{2}}=-\mu_{a} \frac{\partial V_{2}}{\partial y_{k}^{3}} x_{j}^{3}
$$

where $\mu_{a}$ is the learning rate. Comparing (30) with (32), yields $\partial V_{2} / \partial y_{k}^{3}=-e B_{a}$. The convergence analysis in the following theorem is used to derive a specific learning rate to assure the convergence of the output tracking error. The adaptation law of the recurrent weight $w_{i k}^{1}$ by using the gradient descent method can be calculated as:

$$
\begin{aligned}
\dot{w}_{i k}^{1} & =-\mu_{b} \frac{\partial V_{2}}{\partial u_{r e}} \frac{\partial u_{r e}}{\partial y_{k}^{3}} \frac{\partial y_{k}^{3}}{\partial y_{j}^{2}} \frac{\partial y_{j}^{2}}{\partial n o d_{j}^{2}} \frac{\partial \operatorname{nod}_{j}^{2}}{\partial y_{i}^{1}} \frac{\partial y_{i}^{1}}{\partial \operatorname{nod}_{i}^{1}} \frac{\partial \operatorname{nod}_{i}^{1}}{\partial w_{i k}^{1}} \\
& =\mu_{b} B_{a} e w_{k j}^{2} L_{j}(\cdot) x_{i}^{1}(N) y_{k}^{3}(N-1)
\end{aligned}
$$

in which $\mu_{b}$ is the learning rate. Then, two optimal learning rates are derived to assure the convergence of the output tracking error. The convergence analysis is provided in the following two theorems.

Theorem 1: Assume that $\mu_{a}$ is the learning rate of the modified recurrent Legendre NN connective weight between the hidden layer and the output layer. Meanwhile, define $P_{1 \text { wmax }} \quad$ as $\quad P_{1 \text { wmax }} \equiv \max _{N}\left\|P_{1 w}(N)\right\| \quad, \quad$ where $P_{1 w}(N)=\partial y_{k}^{3} / \partial w_{k j}^{2}$, and $\|\cdot\|$ is the Euclidean norm in $\mathfrak{R}^{\mathrm{n}}$. $\mu_{a}$ is chosen as $[30,43]$ :

$$
0<\mu_{a}<\frac{2}{\left(P_{1 w \text { max }}\right)^{2}\left[e B_{a} / e(N)\right]^{2}}
$$

Then, the convergence of the output tracking error is guaranteed. Furthermore, the optimal learning rate, which achieves a fast convergence, can be obtained as:

$$
\mu_{a}^{*}=1 /\left[\left(P_{1 w \max }\right)^{2}\left[e B_{a} / e(N)\right]^{2}\right]
$$

Proof: Since:

$$
P_{1 w}(N)=\partial y_{k}^{3} / \partial w_{k j}^{2}=x_{j}^{3}
$$

The discrete-type Lyapunov function is selected as:

$$
V_{2}(N)=\frac{1}{2} e^{2}(N)
$$

The change in the Lyapunov function is obtained by:

$$
\Delta V_{2}(N)=V_{2}(N+1)-V_{2}(N)=\frac{1}{2}\left[e^{2}(N+1)-e^{2}(N)\right]
$$

Next, the error difference can be represented by:

$$
e(N+1)=e(N)+\Delta e(N)=e(N)+\left[\frac{\partial e(N)}{\partial w_{k j}^{2}}\right]^{T} \Delta w_{k j}^{2}
$$

in which $\Delta e(N)$ is the output error change, and $\Delta w_{k j}^{2}$ represents change in the weight. (39) can be obtained by means of (30), (31), (32) and (36):

$$
\frac{\partial e(N)}{\partial w_{k j}^{2}}=\frac{\partial e(N)}{\partial V_{2}} \frac{\partial V_{2}}{\partial y_{k}^{3}} \frac{\partial y_{k}^{3}}{\partial w_{k j}^{2}}=-\frac{e B_{a}}{e(N)} P_{1 w}(N)
$$




$$
e(N+1)=e(N)-\left[\frac{e B_{a}}{e(N)} P_{1 w}(N)\right]^{T} \mu_{a} e B_{a} P_{1 w}(N)
$$

Thereby:

$$
\begin{aligned}
& \|e(N+1)\|=\left\|e(N)\left[1-\mu_{a}\left(e B_{a} / e(N)\right)^{2} P_{1 w}^{T}(N) P_{1 w}(N)\right]\right\| \\
\leq & \|e(N)\| 1-\mu_{a}\left(e B_{a} / e(N)\right)^{2} P_{1 w}^{T}(N) P_{1 w}(N) \|
\end{aligned}
$$

By means of (38) to (42), the $\Delta V_{2}(N)$ can be rewritten as:

$$
\begin{aligned}
& \Delta V_{2}(N)= \frac{1}{2} \mu_{a}\left[e B_{a}\right]^{2} P_{1 w}^{T}(N) P_{1 w}(N) \\
& \cdot\left\{\mu_{a}\left[e B_{a} / e(N)\right]^{2} P_{1 w}^{T}(N) P_{1 w}(N)-2\right\} \\
& \leq \frac{1}{2} \mu_{a}\left[e B_{a}\right]^{2}\left(P_{1 w \text { max }}(N)\right)^{2} \\
& \\
&\left\{\mu_{a}\left[e B_{a} / e(N)\right]^{2}\left(P_{1 w \text { max }}(N)\right)^{2}-2\right\}
\end{aligned}
$$

If $\mu_{a}$ is chosen as $0<\mu_{a}<2 /\left\{\left(P_{1 w \max }\right)^{2}\left[e B_{a} / e(N)\right]^{2}\right\}$, the Lyapunov stability of $V_{2}(N)>0$ and $\Delta V_{2}<0$ is guaranteed. Then, the output tracking error will converge to zero as $t \rightarrow 0$. This completes the proof of the theorem. Furthermore, the optimal learning rate, which achieves a fast convergence, corresponds to [30, 43]:

$$
2 \mu_{a}^{*}\left\{\left(P_{1 w \max }\right)^{2}\left[e B_{a} / e(N)\right]^{2}\right\}-2=0
$$

i.e.:

$$
\mu_{a}^{*}=1 /\left\{\left(P_{1 w \max }\right)^{2}\left[e B_{a} / e(N)\right]^{2}\right\}
$$

which comes from the derivative of (43) with respect to $\mu_{a}$, and is equal to zero. This produces interesting results for the optimal learning rate which can be on-line tuned at each instant.

Theorem 2: Assume that $\mu_{b}$ is the learning rate of the modified recurrent Legendre NN recurrent weight between the output layer and the input layer. Meanwhile, $P_{2 w \max }$ should be defined as $P_{2 w \max } \equiv \max _{N}\left\|P_{2 w}(N)\right\|$, where $P_{2 w}(N)=\partial y_{k}^{3} / \partial w_{i k}^{1}$, and $\|\cdot\|$ is the Euclidean norm in $\mathfrak{R}^{\mathrm{n}}$. $\mu_{b}$ is chosen as[30, 43]:

$$
0<\mu_{b}<\frac{2}{\left(P_{2 w \max }\right)^{2}\left[B_{a} e / e(N)\right]^{2}}
$$

Then, the convergence of the output tracking error is guaranteed. Furthermore, the optimal learning rate which achieves a fast convergence can be obtained as:

$$
\mu_{b}^{*}=1 /\left\{\left(P_{2 w \max }\right)^{2}\left[B_{a} e / e(N)\right]^{2}\right\}
$$

\section{Proof: Since:}

$$
P_{2 w}(N)=y_{k}^{3} / \partial w_{i k}^{1}=w_{k j}^{2} L_{j}(\cdot) x_{i}^{1}(N) y_{k}^{3}(N-1)
$$

The discrete-type Lyapunov function can be selected as (36) and the change in the Lyapunov function is obtained by (37). Then, the error difference can be represented by:

$$
e(N+1)=e(N)+\Delta e(N)=e(N)+\left[\frac{\partial e(N)}{\partial w_{i k}^{1}}\right]^{T} \Delta w_{i k}^{1}
$$

where $\Delta e(N)$ is the output error change, and $\Delta w_{i k}^{1}$ represents change in the weight. (49) by using (31), (33) and (48), can be represented as:

$$
\begin{gathered}
\frac{\partial e(N)}{\partial w_{i k}^{1}}=\frac{\partial e(N)}{\partial V_{2}} \frac{\partial V_{2}}{\partial y_{k}^{3}} \frac{\partial y_{k}^{3}}{\partial w_{i k}^{1}}=-\frac{B_{a} e}{e(N)} P_{2 w}(N) \\
e(N+1)=e(N)-\left[\frac{B_{a} e}{e(N)} P_{2 w}(N)\right]^{T} \mu_{b} B_{a} e P_{2 w}(N)
\end{gathered}
$$

Thereby:

$$
\begin{gathered}
\|e(N+1)\|=\left\|e(N)\left[1-\mu_{b}\left(B_{a} e l e(N)\right)^{2} P_{2 w}^{T}(N) P_{2 w}(N)\right]\right\| \\
\leq\|e(N)\| 1-\mu_{b}\left(B_{a} e / e(N)\right)^{2} P_{2 w}^{T}(N) P_{2 w}(N) \|
\end{gathered}
$$

By using (38), (49) to (52), $\Delta V_{2}(N)$ can be rewritten as:

$$
\begin{aligned}
\Delta V_{2}(N)= & \frac{1}{2} \mu_{b}\left[B_{a} e\right]^{2} P_{2 w}^{T}(N) P_{2 w}(N) \\
& \left\{\mu_{b}\left[B_{a} e / e(N)\right]^{2} P_{2 w}^{T}(N) P_{2 w}(N)-2\right\} \\
& \leq \frac{1}{2} \mu_{b}\left[B_{a} e\right]^{2}\left(P_{2 w \max }(N)\right)^{2} \\
& \left\{\mu_{b}\left[B_{a} e / e(N)\right]^{2}\left(P_{2 w \max }(N)\right)^{2}-2\right\}
\end{aligned}
$$

If $\mu_{b}$ is chosen as $0<\mu_{b}<2 /\left\{\left(P_{2 w \text { max }}\right)^{2}\left[B_{a} e / e(N)\right]^{2}\right\}$, the Lyapunov stability of $V_{2}(N)>0$ and $\Delta V_{2}(N)<0 \quad$ is guaranteed. Then, the output tracking error will converge to zero as $t \rightarrow 0$.This completes the proof of the theorem. Moreover, the optimal learning rate, which achieves fast convergence, corresponds to $[30,43]$ :

$$
2 \mu_{b}^{*}\left\{\left(P_{2 w \max }\right)^{2}\left[B_{a} e / e(N)\right]^{2}\right\}-2=0
$$

i.e.:

$$
\mu_{b}^{*}=1 /\left\{\left(P_{2 w \max }\right)^{2}\left[B_{a} e / e(N)\right]^{2}\right\}
$$

which comes from the derivative of (53) with respect to $\mu_{b}$, and is equal to zero. This produces interesting results for the optimal learning rate which can be on-line tuned at each instant. In summary, the online tuning algorithm for the modified recurrent Legendre $\mathrm{NN}$ controller is based on the adaptation laws (32) and (33) for the connective weight adjustment and the recurrent weights adjustment with the two optimal learning rates in (35) and (47), respectively. Moreover, the modified recurrent Legendre NN weight estimation errors are fundamentally bounded [44].The modified recurrent Legendre NN weight estimation errors are 
bounded, which is required to ensure that the control signal is bounded.

\section{EXPERIMENTAL RESULTS}

The whole system of the DSP-based control system for a V-belt CVT driven electric scooter using a PMSM servo drive system is shown in Fig.1. A photo of the experimental setup is shown in Fig. 4. The control algorithm was executed by a TMS320C32 DSP control system including multi-channels of $\mathrm{D} / \mathrm{A}$, eight channels programmable PWM and an encoder interface circuit. The methodologies proposed for the real-time control implementation in the DSP control system are composed of the main program and the interrupt service routine (ISR), as shown in Fig. 5. In the main program, the parameters and input/output (I/O) initializations are processed first. Then, the interrupt interval for the ISR is set. After enabling the interrupt, the main program is used to monitor the control data. The ISR with a $2 m s$ sampling interval is used for reading the rotor position of the PMSM servo-driven electric scooter from the encoder, and the three-phase currents from the $\mathrm{A} / \mathrm{D}$ converter. This is done by calculating the rotor position and speed, executing the lookup table and the coordinate translation, executing the PI current control, executing the novel hybrid modified recurrent Legendre NN control system, and outputting the three-phase current commands to the sinusoidal PWM circuit for switching the three-sets of IGBT power module inverters via the interlock and isolated circuits. The IGBT power module voltage source inverter is executed by a current-controlled sinusoidal PWM with a switching frequency of $15 \mathrm{kHz}$ by using a triangular carrier wave. In addition, the measured bandwidth of the speed control loop is about $24 \mathrm{~Hz}$, and the measured bandwidth of the current control loop by no load is about $240 \mathrm{~Hz}$ for a PMSM servo-drive system without mounted V-bet CVT and wheel systems. The specifications of the surface-mounted PMSM are a three-phase $48 \mathrm{~V}, 750 \mathrm{~W}, 16.5 \mathrm{~A}, 3600 \mathrm{rpm}$. The parameters of the PMSM are given as follows: $\bar{J}_{1}=2.15 \times 10^{-3} \mathrm{Nms}, \bar{B}_{1}=6.18 \times 10^{-3} \mathrm{Nms} / \mathrm{rad}, \quad k_{r}=0.86 \mathrm{Nm} / \mathrm{A}$, $R_{1}=2.5 \Omega$, and $L_{d 1}=L_{q 1}=6.53 \mathrm{mH}$ by using an open circuit test, short test, rotor block test, and loading test. To show the control performance of the proposed novel hybrid modified recurrent Legendre NN control system, three cases are provided in the experimentation. These cases are the125.6rad/s $(1200 \mathrm{rpm})$ case, the $251.2 \mathrm{rad} / \mathrm{s}(2400 \mathrm{rpm})$ case and $376.8 \mathrm{rad} / \mathrm{s}(3600 \mathrm{rpm})$ case. With this application it is necessary to decrease the bandwidth of the speed due

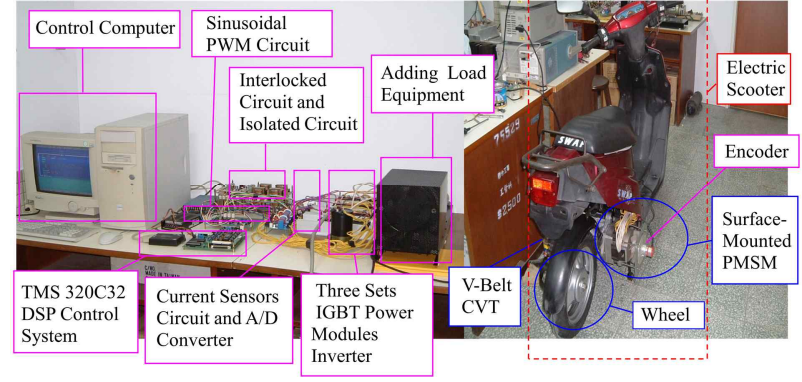

Fig. 4. Photo of the experimental setup.
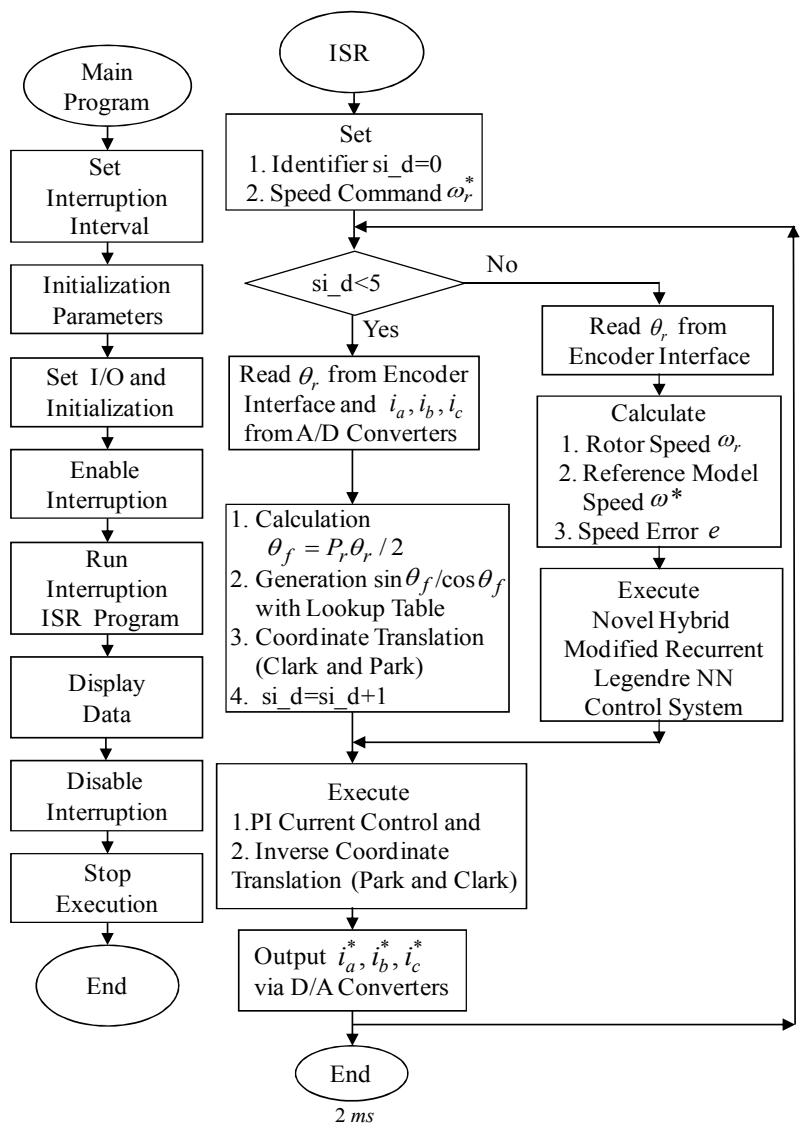

Fig. 5. Flowchart of the executing program by using the DSP control system.

to high stiffness between the motor and the nonlinear load. This is especially true with an electric scooter mounted with V-bet CVT and wheel systems. Therefore, the adopted three bandwidths of the speed control loop with the three reference models in the $125.6 \mathrm{rad} / \mathrm{s}(1200 \mathrm{rpm})$ case, the $251.2 \mathrm{rad} / \mathrm{s}(2400 \mathrm{rpm}) \mathrm{case}$, and the $376.8 \mathrm{rad} / \mathrm{s}$ (3600 rpm) case are about $6.25 \mathrm{~Hz}, 2.8 \mathrm{~Hz}$, and $2.0 \mathrm{~Hz}$, respectively.

Since an electric scooter is a nonlinear and time-varying system, all of the gains of the well-known PI controller are $k_{p s}=13.5, \quad k_{i s}=k_{p s} / T_{i s}=1.8$ through some heuristic knowledge [38-40] on the tuning of the PI controller in the 125.6rad/s (1200 rpm) case for speed tracking in order to achieve good transient and steady-state control performances. 
The experimental results of the well-known PI controller for the V-belt CVT driven electric scooter using the PMSM servo drive system in the125.6 rad/s $(1200 \mathrm{rpm})$ case and in the $251.2 \mathrm{rad} / \mathrm{s}(2400 \mathrm{rpm})$ case are shown in Fig. 6 and Fig. 7 , respectively.

The responses of the rotor speed command $\omega_{r}^{*}$, the desired rotor speed command $\omega^{*}$ and the measured rotor speed $\omega_{r}$ are shown in Fig. 6(a) and Fig. 7(a). The response of the tracking error $e$ amplification is shown in Fig. 6(b) and Fig. 7(b). The tracking response of the current command $i_{a}^{*}$ and the measured current $i_{a}$ in phase $a$ is shown in Fig.6(c) and Fig. 7(c). The dynamic response of the electromagnetic torque $T_{e}$ is shown in Fig. 6(d) and Fig. 7 (d).

In addition, the experimental result of the well-known PI controller for the V-belt CVT driven electric scooter using the PMSM servo drive system in the $376.8 \mathrm{rad} / \mathrm{s}$ (3600 rpm)case under high speed perturbation is shown in Fig.8, where responses of the rotor speed command $\omega_{r}^{*}$, the desired rotor speed command $\omega^{*}$ and the measured rotor speed $\omega_{r}$ are shown in Fig. 8(a). The response of the tracking error $e$ is shown in Fig. 8(b). The response of the tracking error $e$ amplification is shown in Fig. 8(c). The dynamic response of the electromagnetic torque $T_{e}$ is shown in Fig. 8(d). Since the low speed operation is the same as the nominal case due to smaller lumped nonlinear external disturbances, the response of the speed shown in Fig. 6(a) has better tracking performance. In addition, the degenerate tracking response of the speed shown in Fig. 7(a) and Fig. 8 (a) is obvious due to bigger lumped nonlinear disturbances (e.g. rolling resistance and parameter variations)in the 251.2 $\mathrm{rad} / \mathrm{s}(2400 \mathrm{rpm})$ case and in the $376.8 \mathrm{rad} / \mathrm{s}$ (3600 rpm) case. Moreover, the electromagnetic torque brings in a greater torque ripple, as shown in Fig. 6(d), Fig. 7(d) and Fig. 8(d), due to a V-belt CVT system with highly nonlinear external disturbances, such as V-belt shaking friction, and the action friction between the primary pulley and the second pulley. Moreover, the sluggish tracking response of the current shown Fig. 7(c) is obtained for the well-known PI controlled V-belt CVT driven electric scooter using the PMSM servo drive system. The linear controller has weak robustness under larger lumped nonlinear external disturbances in high speed operations due to the lack of appropriately gains tuning or degenerate nonlinear effect.

For comparison, the control performance with the proposed novel hybrid modified recurrent Legendre NN control system, for the three-layer recurrent $\mathrm{NN}$ control system is adopted in this paper. The three-layer recurrent $\mathrm{NN}$ has the recurrent loop between the output layer and the input layer and it has

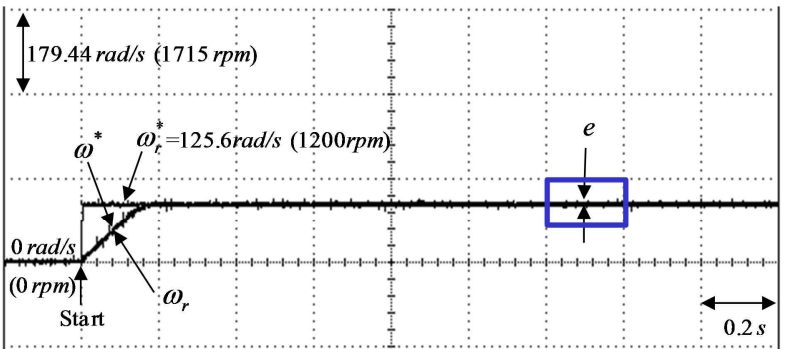

(a)

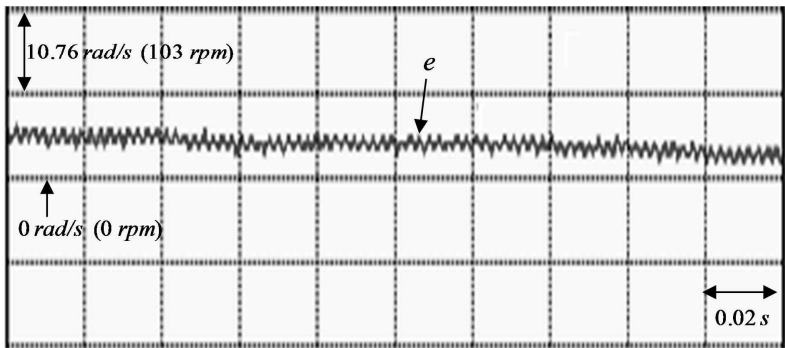

(b)

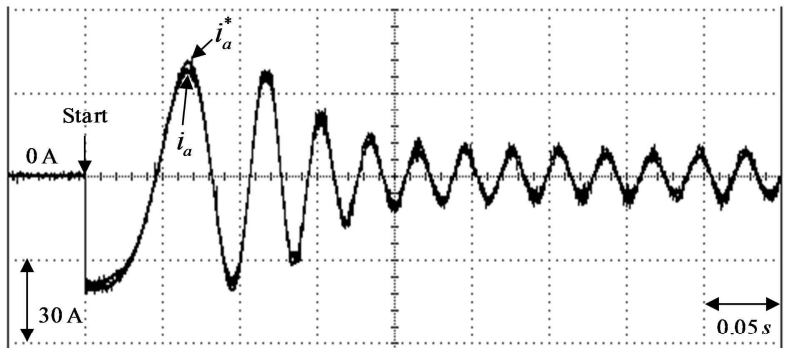

(c)

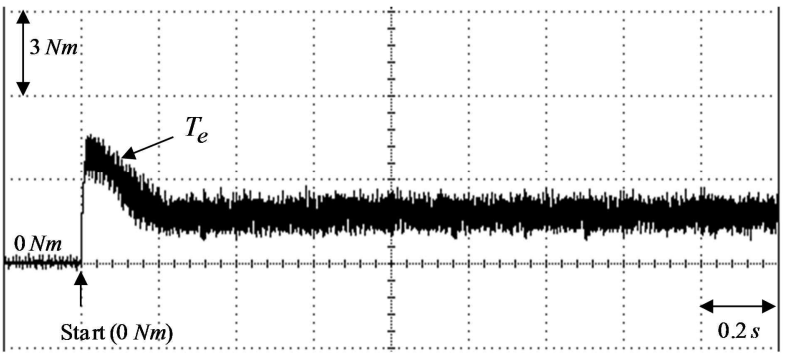

(d)

Fig. 6. Experimental result of the well-known PI controller controlled for the V-belt CVT driven electric scooter by using the PMSM servo drive system at 125.6rad/s (1200rpm): (a) tracking response of rotor speed command $\omega_{r}^{*}$, desired rotor speed command $\omega^{*}$ and measured rotor speed $\omega_{r}$; (b) response of tracking error $e$ amplification; (c) current command $i_{a}^{*}$ and measured current $i_{a}$ in phase $a$; (d) electromagnetic torque $T_{e}$.

the sigmoid activation function in the hidden layer. It has two, three and one neurons in the input layer, the hidden layer and the output layer, respectively. All of the control gains of the three-layer recurrent $\mathrm{NN}$ control system are chosen to achieve the best transient control performance while considering the requirement of stability. For simplicity, the recurrent weight between the output layer and the input layer in the three-layer 


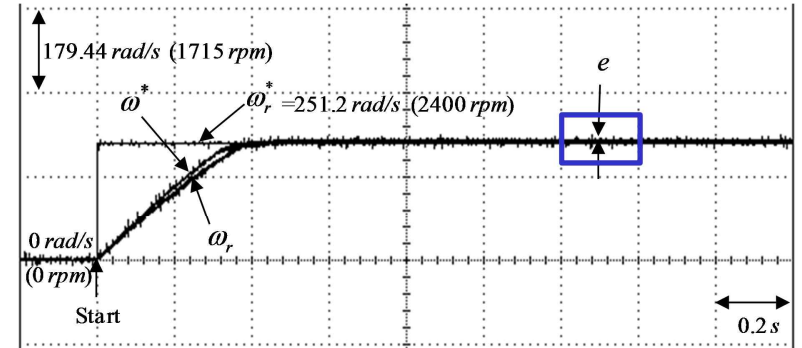

(a)

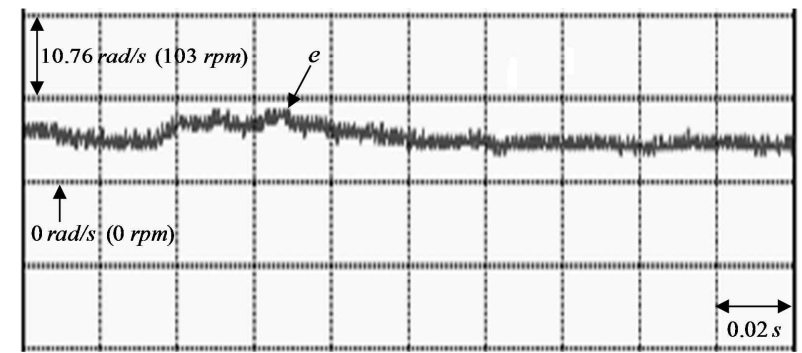

(b)

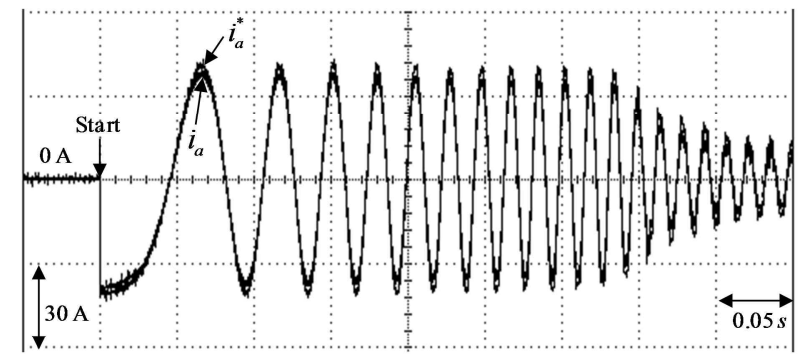

(c)

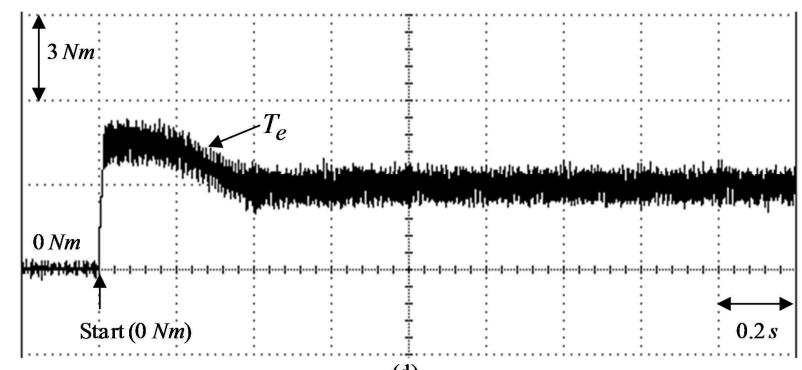

(d)

Fig. 7. Experimental result of the well-known PI controller controlled for the V-belt CVT driven electric scooter by using the PMSM servo drive system at 251.2 rad/s (2400rpm): (a) tracking response of rotor speed command $\omega_{r}^{*}$, desired rotor speed command $\omega^{*}$ and measured rotor speed $\omega_{r} ;$ (b) response of tracking error $e$ amplification ; (c) current command $i_{a}^{*}$ and measured current $i_{a}$ in phase $a$; (d) electromagnetic torque $T_{e}$.

recurrent $\mathrm{NN}$ is to set 1 . Moreover, the connective weight between the input layer and the hidden layer, and the connective weight between the hidden layer and the output layer in the three-layer recurrent $\mathrm{NN}$ are initialized with random numbers. In addition, all of the learning rates are set as fixed constants. Furthermore, the normalized inputs and references have zero and unity, respectively. Also the

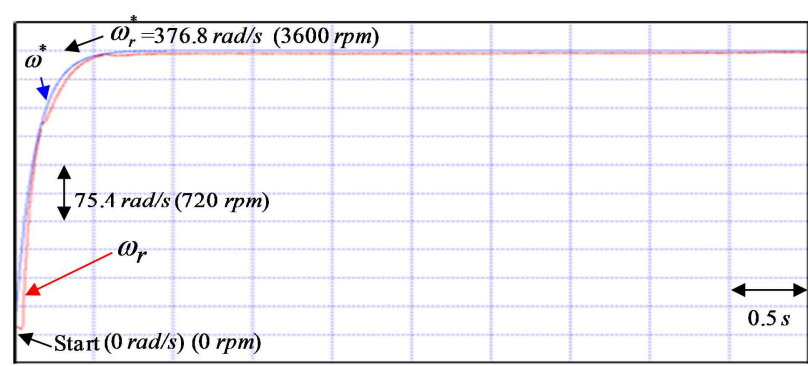

(a)

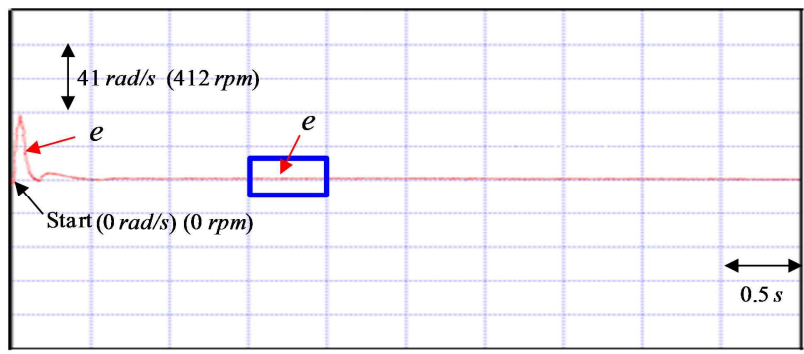

(b)

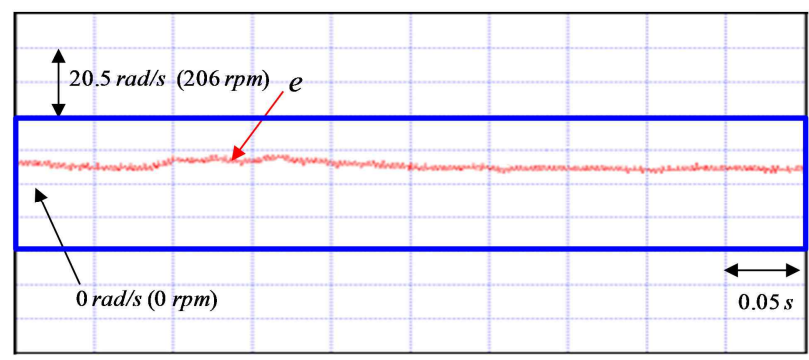

(c)

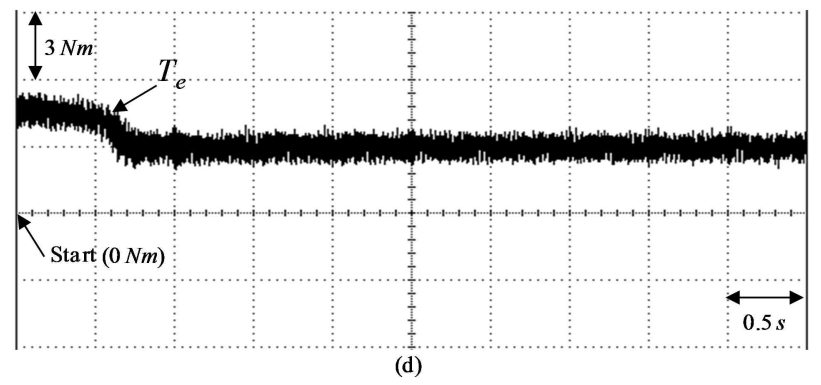

Fig. 8. Experimental results of the well-known PI controlled for the V-belt CVT driven electric scooter by using the PMSM servo drive system at $376.8 \mathrm{rad} / \mathrm{s}$ (3600rpm): (a) tracking response of rotor speed command $\omega_{r}^{*}$, desired rotor speed command $\omega^{*}$ and measured rotor speed $\omega_{r}$; (b) response of tracking error $e$; (c)response of tracking error $e$ amplification ; (d) electromagnetic torque $T_{e}$.

network outputs should be converted back to the original units of reference. The parameter adjustment process remains continually active for the duration of the experiment. The experimental results of the three-layer recurrent $\mathrm{NN}$ control system for the V-belt CVT driven electric scooter using the PMSM servo drive system in the $125.6 \mathrm{rad} / \mathrm{s}(1200 \mathrm{rpm})$ case and the $251.2 \mathrm{rad} / \mathrm{s}(2400 \mathrm{rpm})$ case are shown in Fig. 9 and Fig. 10. The response of the rotor speed command $\omega_{r}^{*}$, the 


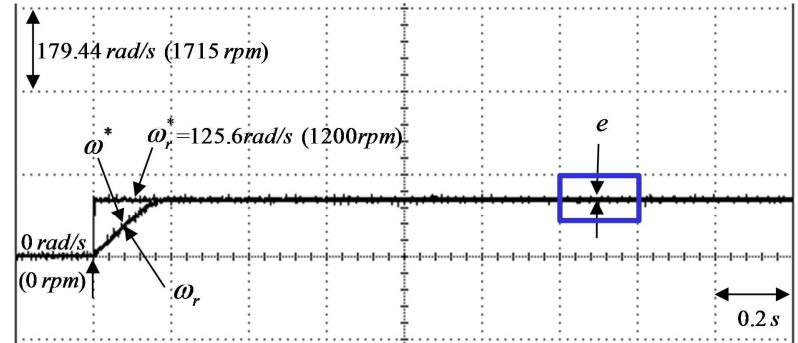

(a)

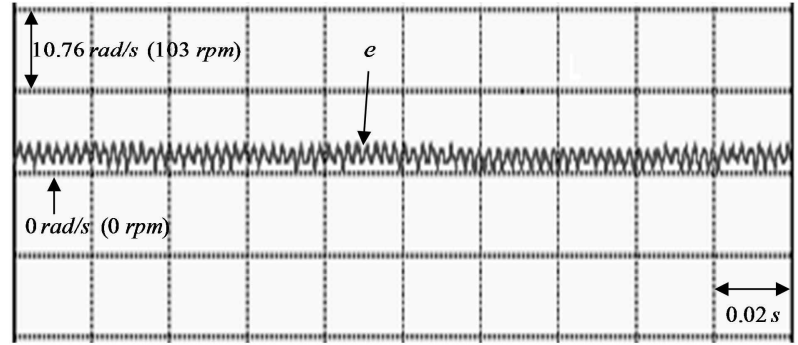

(b)

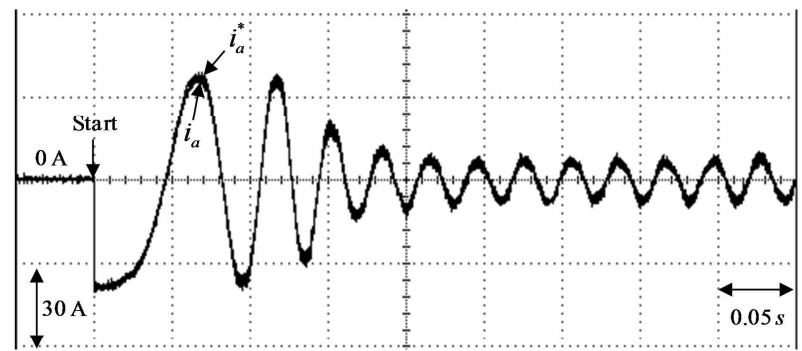

(c)

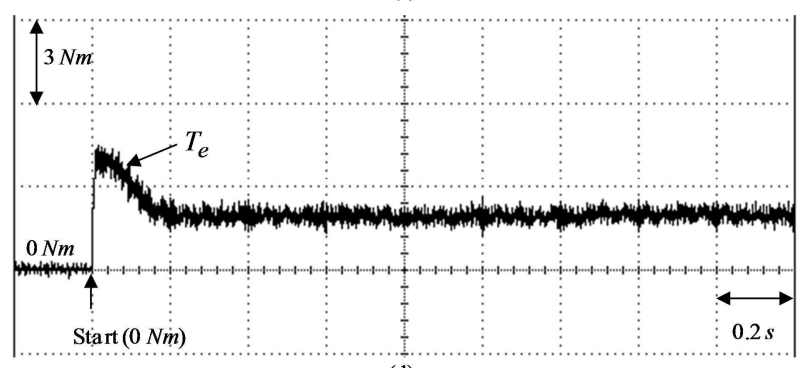

(d)

Fig. 9. Experimental results of the three-layer recurrent $\mathrm{NN}$ control system controlled for the V-belt CVT driven electric scooter by using the PMSM servo drive system at $125.6 \mathrm{rad} / \mathrm{s}$ (1200rpm): (a) tracking response of rotor speed command $\omega_{r}^{*}$, desired rotor speed command $\omega^{*}$ and measured rotor speed $\omega_{r}$; (b) response of tracking error $e$ amplification; (c) current command $i_{a}^{*}$ and measured current $i_{a}$ in phase $a$; (d) electromagnetic torque $T_{e}$.

desired rotor speed $\omega^{*}$ and the measured rotor speed $\omega_{r}$ are shown in Figs. 9(a) and Fig. 10(a). The response of the tracking error $e$ amplification is shown in Fig. 9(b) and Fig. 10(b). The tracking response of the current command $i_{a}^{*}$ and the measured current $i_{a}$ in phase $a$ are shown in Fig. 9(c) and Fig. 10(c). The dynamic response of the

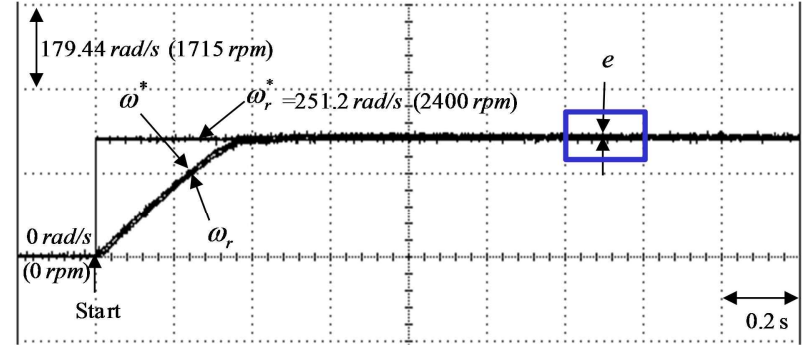

(a)

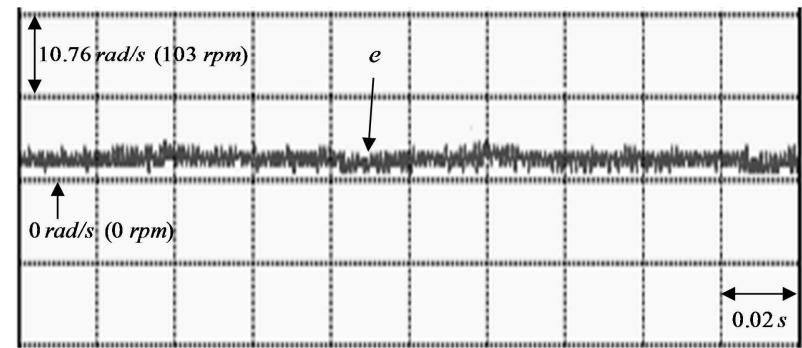

(b)

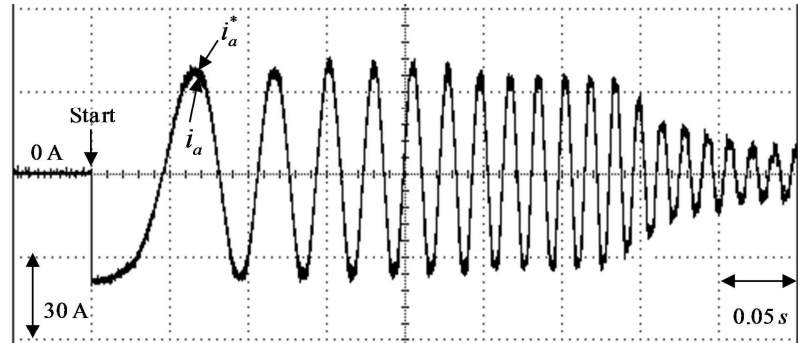

(c)

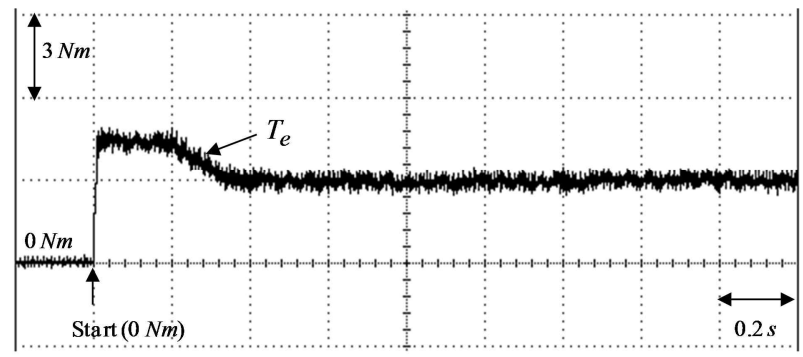

(d)

Fig. 10. Experimental results of the three-layer recurrent NN control system controlled for the V-belt CVT driven electric scooter by using the PMSM servo drive system at $251.2 \mathrm{rad} / \mathrm{s}$ (2400rpm): (a) tracking response of rotor speed command $\omega_{r}^{*}$, desired rotor speed command $\omega^{*}$ and measured rotor speed $\omega_{r}$; (b) response of tracking error $e$ amplification ; (c) current command $i_{a}^{*}$ and measured current $i_{a}$ in phase $a$; (d) electromagnetic torque $T_{e}$.

electromagnetic torque $T_{e}$ is shown in Fig. 9(d) and Fig. 10(d). In addition, the experimental results of the three-layer recurrent $\mathrm{NN}$ control system for the V-belt CVT driven electric scooter using the PMSM servo drive system in the $376.8 \mathrm{rad} / \mathrm{s}$ (3600rpm) case under a high speed perturbation is shown in Fig.11, where response of the rotor speed command $\omega_{r}^{*}$, the desired rotor speed command $\omega^{*}$ and the 


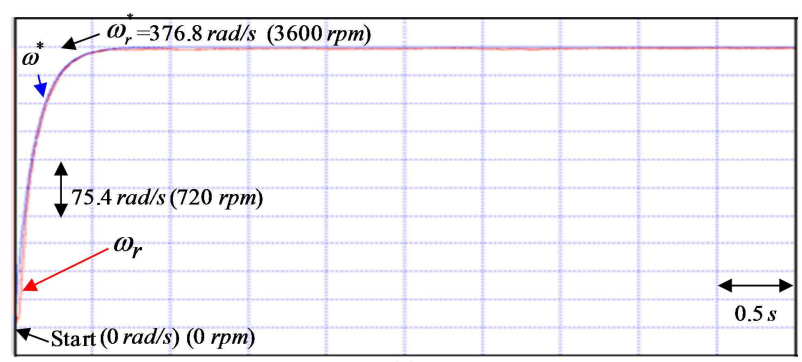

(a)

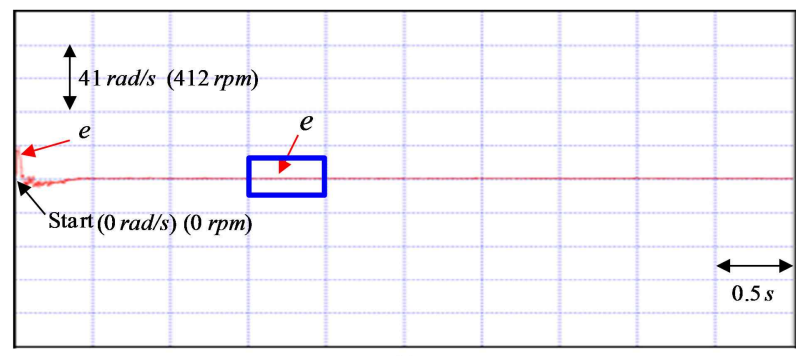

(b)

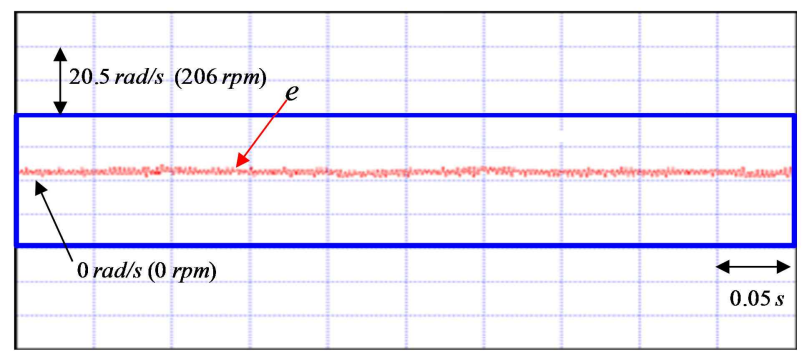

(c)

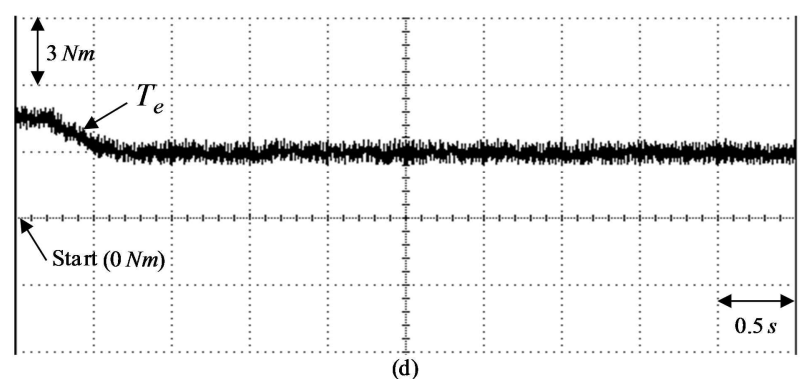

Fig. 11. Experimental results of the three-layer recurrent $\mathrm{NN}$ control system controlled for the V-belt CVT driven electric scooter by using the PMSM servo drive system at $376.8 \mathrm{rad} / \mathrm{s}$ (3600rpm): (a) tracking response of rotor speed command $\omega_{r}^{*}$, desired rotor speed command $\omega^{*}$ and measured rotor speed $\omega_{r}$; (b) response of tracking error $e$; (c)response of tracking error $e$ amplification; (d) electromagnetic torque $T_{e}$.

measured rotor speed $\omega_{r}$ are shown in Fig. 11(a). The response of the tracking error $e$ is shown in Fig. 11(b). The response of the tracking error $e$ amplification is shown in Fig. 11(c).The dynamic response of the electromagnetic torque $T_{e}$ is shown in Fig. 11(d).

However, due to the on-line adaptive mechanism of the three-layer recurrent NN and the recouped controller, accurate tracking responses of the speed and current can be obtained. These experimental results show that the three-layer recurrent NN control system has better control performance than the well-known PI controller for the V-belt CVT driven electric scooter using the PMSM servo drive system in the $251.2 \mathrm{rad} / \mathrm{s}(2400 \mathrm{rpm})$ case and in the $376.8 \mathrm{rad} / \mathrm{s}$ (3600rpm) case under the occurrence of large lumped nonlinear disturbances. Meanwhile, the electromagnetic torque $T_{e}$ exhibits a lower torque ripple, as shown in Fig. 9(d), Fig. 10(d) and Fig. 11(d).

The control gains of the proposed novel hybrid modified recurrent Legendre NN control system are $\eta=0.1, \lambda=0.5$ according to the estimated uncertainty bound for the recouped controller compensating perturbations in order to achieve the best transient control performance. All of the control gains of the novel hybrid modified recurrent Legendre NN control system are chosen to achieve the best transient control performance, while considering the requirement of stability. Usually, some heuristics can be used to roughly initialize the parameters of the novel hybrid modified recurrent Legendre NN control system for practical applications. The effects of the inaccurate selection of the initialized parameters can be retrieved by the online parameter training methodology. For simplicity, all of the recurrent weights between the output layer and the input layer in the modified recurrent Legendre $\mathrm{NN}$ are to set to 1 . Moreover, the connective weights between the hidden layer and the output layer in the modified recurrent Legendre $\mathrm{NN}$ are initialized with a random number. Furthermore, the normalized inputs and references are zero and unity, respectively. In addition, the network outputs should be converted back to the original units of the references. The parameter adjustment process remains continually active for the duration of the experiment. The structure of the modified recurrent Legendre NN controller has 2 nodes, 3 nodes and 1 node in the input layer, the hidden layer and the output layer, respectively. The experimental results of the novel hybrid modified recurrent Legendre NN control system for the V-belt CVT driven electric scooter using the PMSM servo drive system in the125.6 rad/s (1200 $\mathrm{rpm}$ ) case and in the $251.2 \mathrm{rad} / \mathrm{s}(2400 \mathrm{rpm})$ case are shown in Fig. 12 and Fig. 13. The response of the rotor speed command $\omega_{r}^{*}$, the desired rotor speed command $\omega^{*}$ and the measured rotor speed $\omega_{r}$ are shown in Fig. 12(a) and Fig. 13(a). The response of the tracking error $e$ amplification is shown in Fig. 12(b) and Fig. 13(b). The tracking response of the current command $i_{a}^{*}$ and the measured current $i_{a}$ in phase $a$ are shown in Fig. 12(c) and Fig. 13(c). The dynamic response of the electromagnetic torque $T_{e}$ is shown in Fig. 12(d) and Fig. 13(d). In addition, the experimental results of novel hybrid modified recurrent Legendre NN control system 


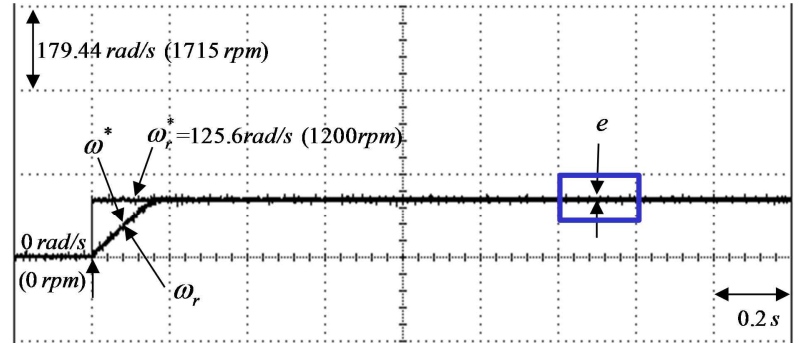

(a)

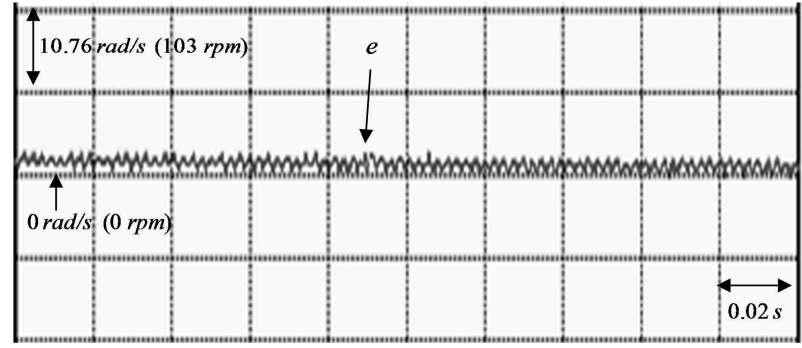

(b)

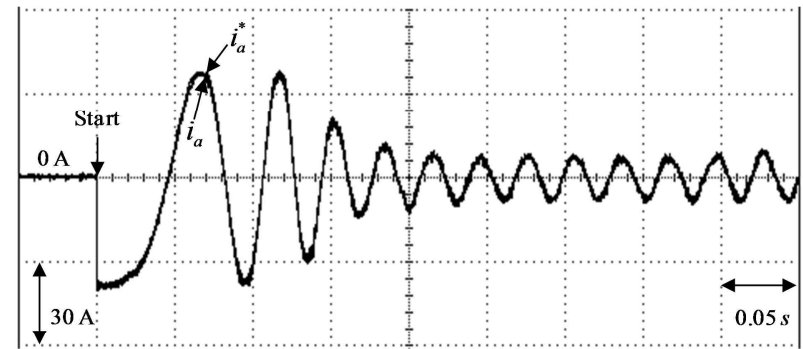

(b)

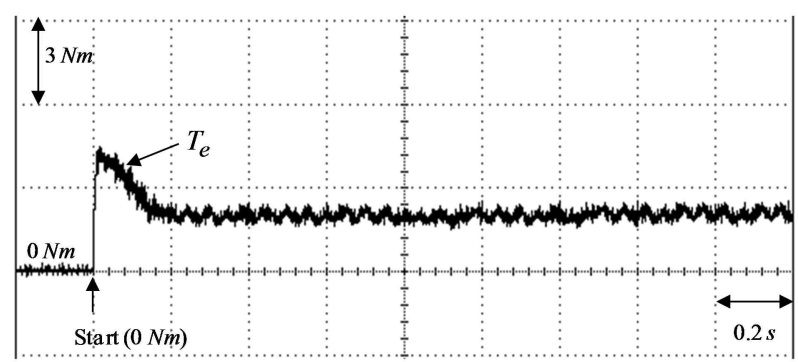

(c)

Fig. 12. Experimental results of the novel hybrid modified recurrent Legendre NN control system controlled for the V-belt CVT driven electric scooter by using the PMSM servo drive system at $125.6 \mathrm{rad} / \mathrm{s}$ (1200rpm): (a) tracking response of rotor speed command $\omega_{r}^{*}$, desired rotor speed command $\omega^{*}$ and measured rotor speed $\omega_{r}$; (b) response of tracking error $e$ amplification ; (c) current command $i_{a}^{*}$ and measured current $i_{a}$ in phase $a$; (d) electromagnetic torque $T_{e}$.

for the V-belt CVT driven electric scooter using the PMSM servo drive system in the $376.8 \mathrm{rad} / \mathrm{s}(3600 \mathrm{rpm})$ case under high speed perturbations is shown in Fig.14. The response of the rotor speed command $\omega_{r}^{*}$, the desired rotor speed command $\omega^{*}$ and the measured rotor speed $\omega_{r}$ are shown in Fig. 14(a). The response of the tracking error $e$ is shown

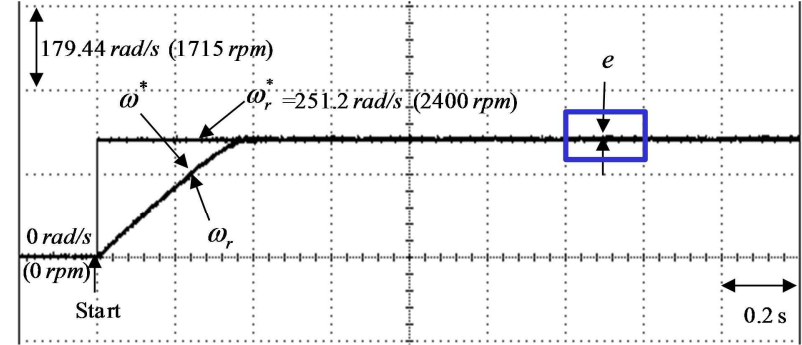

(a)

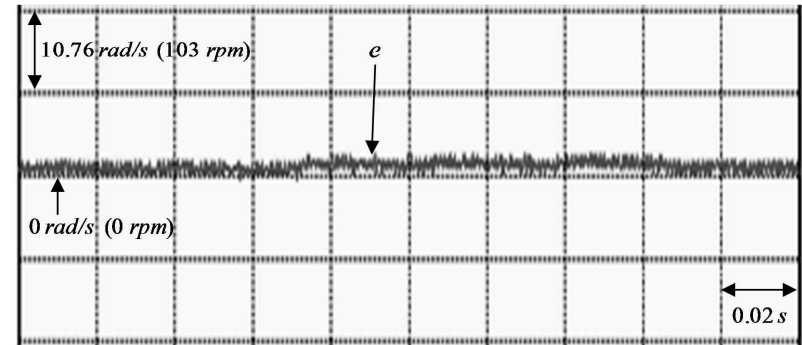

(b)

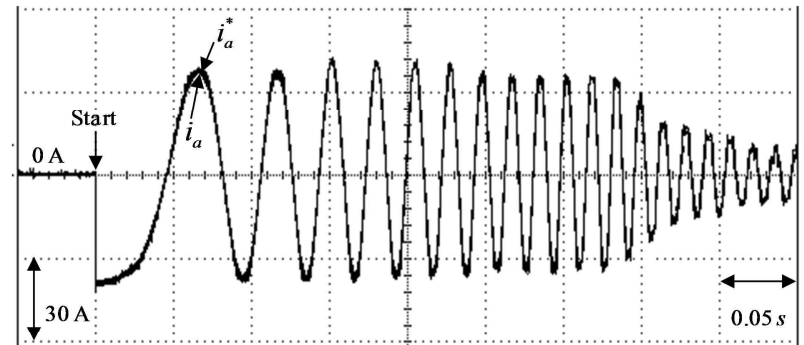

(b)

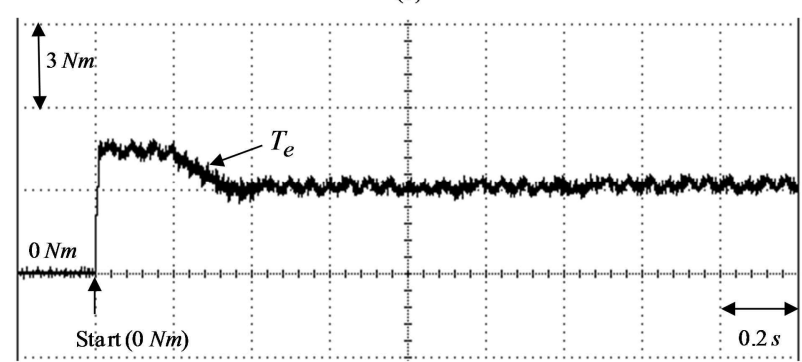

(c)

Fig. 13. Experimental results of the novel hybrid modified recurrent Legendre NN control system controlled for the V-belt CVT driven electric scooter by using the PMSM servo drive system at 251.2 rad/s (2400rpm): (a) tracking response of rotor speed command $\omega_{r}^{*}$, desired rotor speed command $\omega^{*}$ and measured rotor speed $\omega_{r}$; (b) response of tracking error $e$ amplification ; (c) current command $i_{a}^{*}$ and measured current $i_{a}$ in phase $a$; (d) electromagnetic torque $T_{e}$.

in Fig. 14(b). The response of the tracking error $e$ amplification is shown in Fig. 14(c).The dynamic response of the electromagnetic torque $T_{e}$ is shown in Fig. 14(d).

From the experimental results, accurate tracking performance is obtained for the novel hybrid modified recurrent Legendre NN controller for the V-belt CVT driven electric scooter using the PMSM servo drive owing to the 


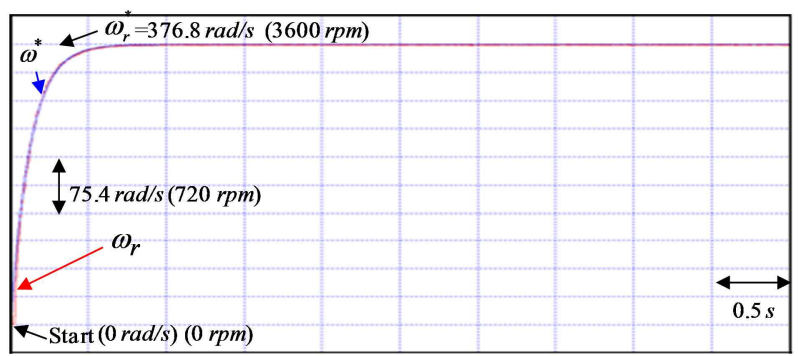

(a)

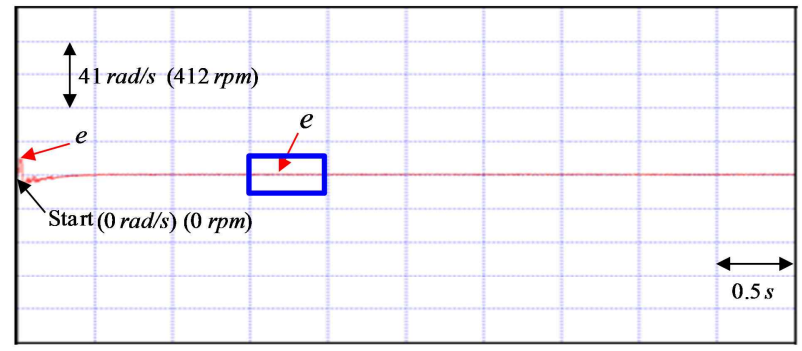

(b)

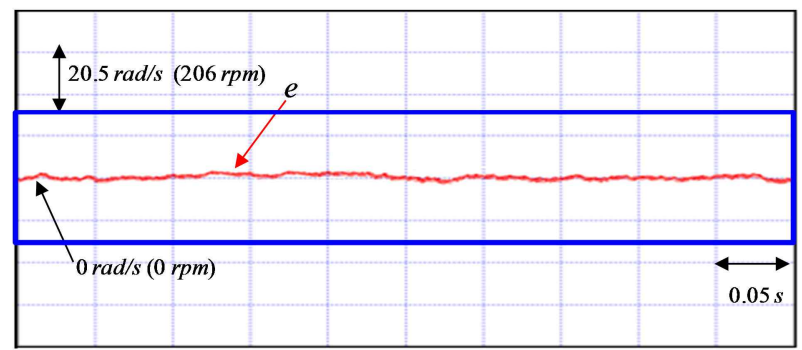

(c)

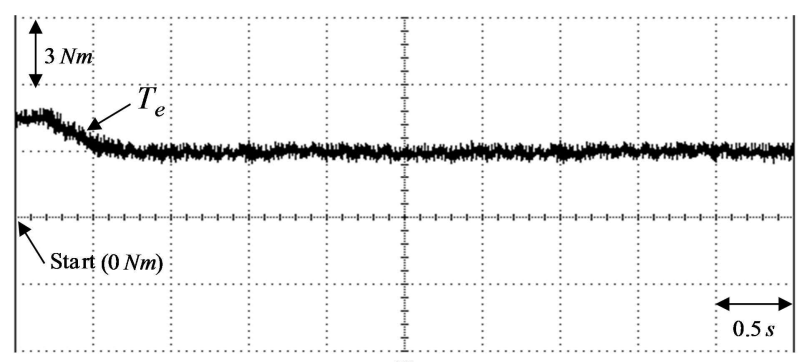

(d)

Fig. 14. Experimental results of the novel hybrid modified recurrent Legendre NN control system controlled for the V-belt CVT driven electric scooter by using the PMSM servo drive system at $376.8 \mathrm{rad} / \mathrm{s}$ (3600rpm): (a) tracking response of rotor speed command $\omega_{r}^{*}$, desired rotor speed command $\omega^{*}$ and measured rotor speed $\omega_{r}$; (b) response of tracking error $e$; (c)response of tracking error $e$ amplification ; (d) electromagnetic torque $T_{e}$.

on-line adaptive mechanism of the modified recurrent Legendre NN and action of the recouped controller. Therefore, these results show that the novel hybrid modified recurrent Legendre NN control system has better control performance than the well-known PI controller for speed perturbations for the V-belt CVT driven electric scooter using the PMSM servo drive system.

Additionally, the small chattering phenomena of the

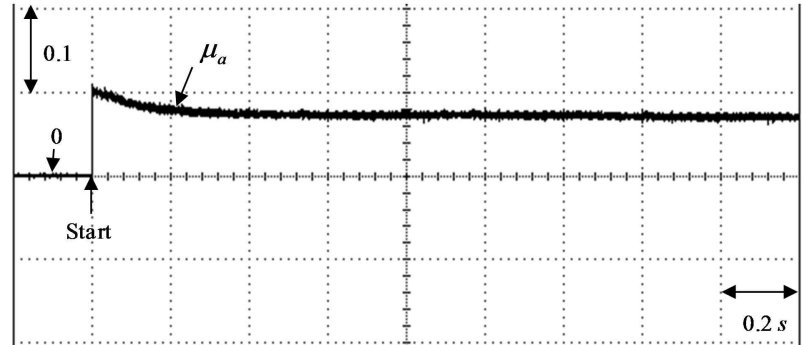

(a)

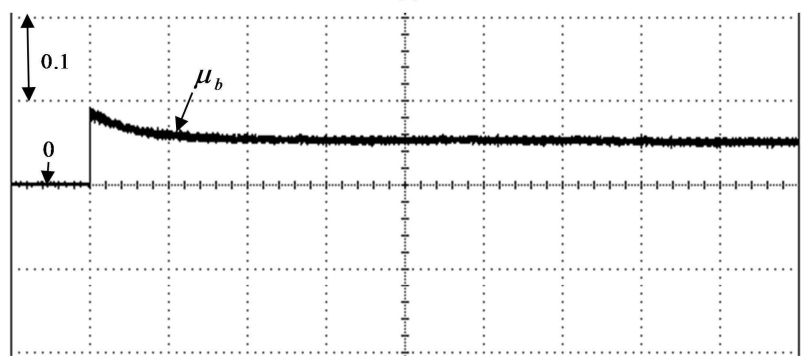

(b)

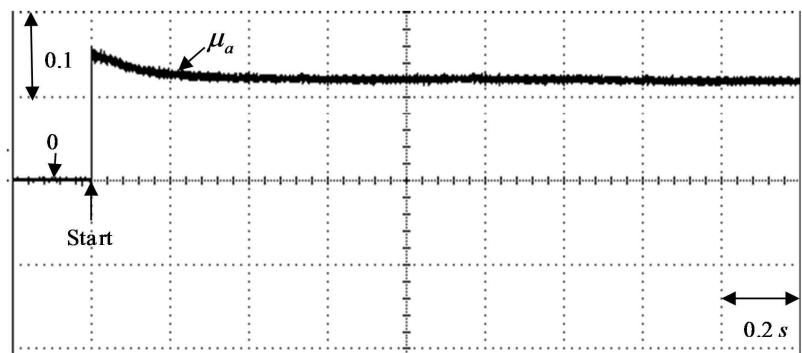

(c)

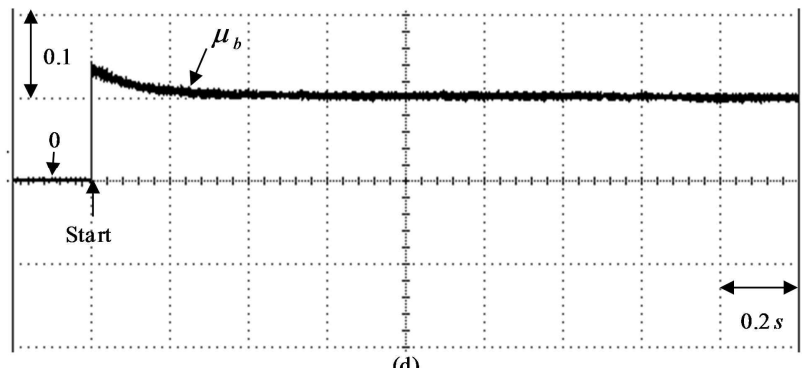

(d)

Fig. 15. Experimental result of the learning rate variations in the modified recurrent Legendre NN: (a) response of the learning rate $\mu_{a}$ the connection weights at $125.6 \mathrm{rad} / \mathrm{s}(1200 \mathrm{rpm})$ case; (b) response of the learning rate $\mu_{b}$ of the recurrent weights at $125.6 \mathrm{rad} / \mathrm{s}(1200 \mathrm{rpm})$ case; (c) response of the learning rate $\mu_{a}$ of the connection weights at $251.2 \mathrm{rad} / \mathrm{s}$ (2400 rpm) case; (d) response of the learning rate $\mu_{b}$ of the recurrent weights at $251.2 \mathrm{rad} / \mathrm{s}(2400 \mathrm{rpm})$.

currents in phase $a$, shown in Fig. 9(c), Fig. 10(c) and Fig. 12(c) and Fig. 13(c), are induced by on-line adjustments of the three-layer recurrent $\mathrm{NN}$ and the novel hybrid modified recurrent Legendre NN, respectively, to cope with the highly nonlinear dynamics of the system.

Furthermore, the speed response, shown in Fig. 13(a) and Fig. 14(a) from using the novel hybrid modified recurrent 


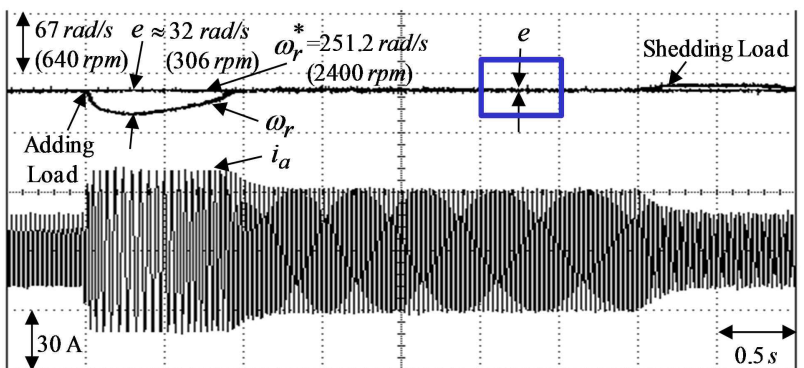

(a)

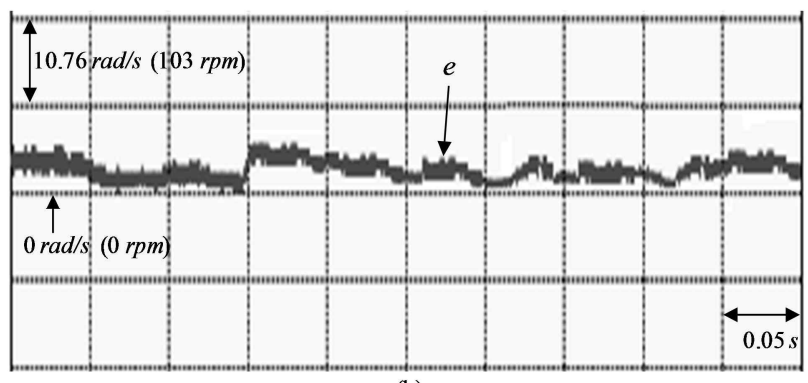

(b)

Fig. 16. Experimental results under $T_{l}=2 \mathrm{Nm}\left(T_{a}\right)+T_{u n}$ load disturbance with adding load and shedding load at 251.2 $\mathrm{rad} / \mathrm{s}(2400 \mathrm{rpm})$ case by using the well-known PI controller: (a) command rotor angular speed $\omega_{r}^{*}$, measured rotor angular speed $\omega_{r}$ and measured current $i_{a}$ in phase $a$; (b) amplified speed error $e$.

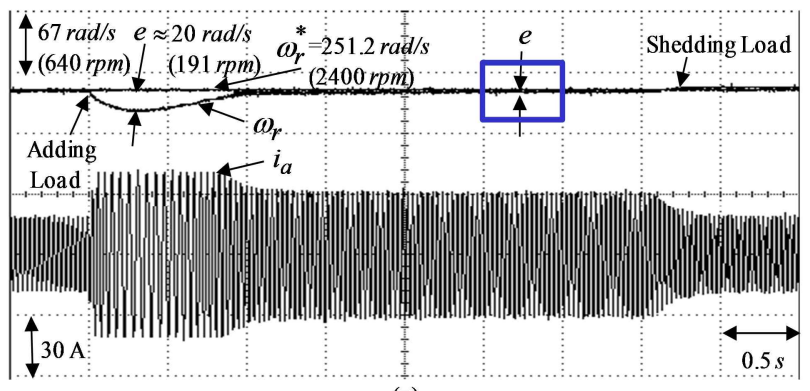

(a)

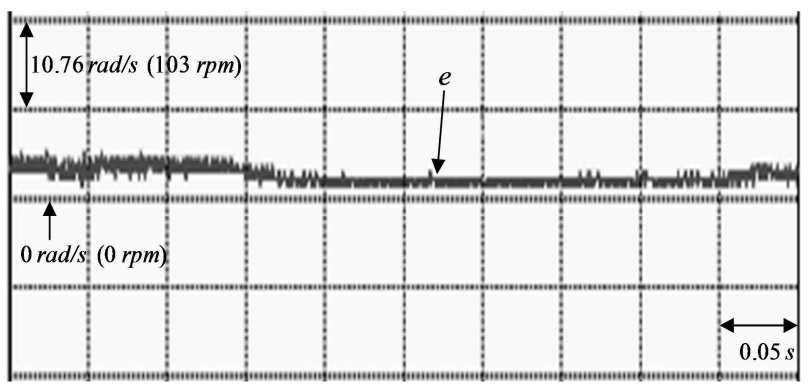

(b)

Fig. 17. Experimental results under $T_{l}=2 \mathrm{Nm}\left(T_{a}\right)+T_{u n}$ load disturbance with adding load and shedding load at 251.2 $\mathrm{rad} / \mathrm{s}(2400 \mathrm{rpm})$ case by using the three-layer recurrent $\mathrm{NN}$ control system: (a) command rotor angular speed $\omega_{r}^{*}$, measured rotor angular speed $\omega_{r}$ and measured current $i_{a}$ in phase $a$; (b) amplified speed error $e$.

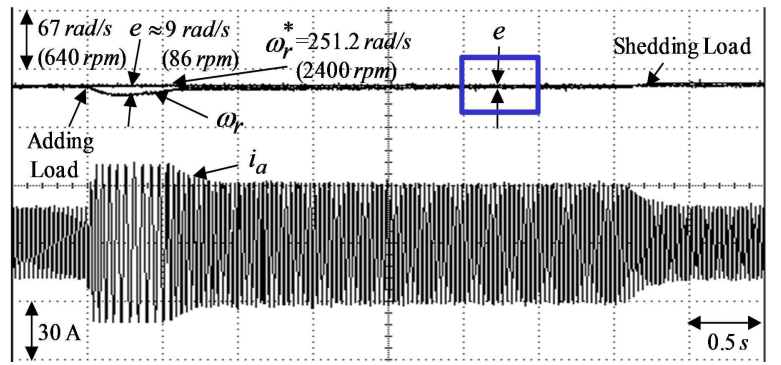

(a)

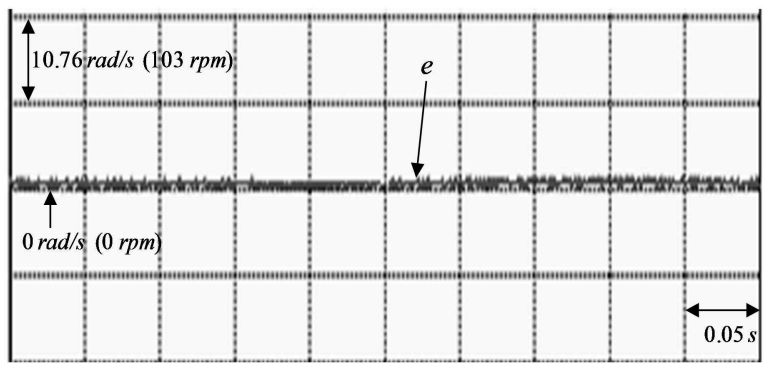

(b)

Fig. 18. Experimental results under $T_{l}=2 \mathrm{Nm}\left(T_{a}\right)+T_{u n}$ load disturbance with adding load and shedding load at 251.2 $\mathrm{rad} / \mathrm{s}(2400 \mathrm{rpm})$ case by using the novel hybrid modified recurrent Legendre NN control system: (a) command rotor angular speed $\omega_{r}^{*}$, measured rotor angular speed $\omega_{r}$ and measured current $i_{a}$ in phase $a$; (b) amplified speed error $e$.

Legendre NN control system due to its lower computational complexity, has a faster convergence than the speed response shown in Fig. 10(a) and Fig. 11(a) by using the three-layer recurrent $\mathrm{NN}$ control system in the $251.2 \mathrm{rad} / \mathrm{s}$ (2400 rpm) case and in the $376.8 \mathrm{rad} / \mathrm{s}$ (3600rpm) case. Moreover, the dynamic response of electromagnetic torque $T_{e}$, shown in

Fig. 12(d), Fig. 13(d) and Fig. 14(d), from using the novel hybrid modified recurrent Legendre NN control system has a lower torque ripple than that obtained using the well-known PI control and the three-layer recurrent NN control system shown in Fig. 5(d), Fig. 6(d), Fig. 7(d) and in Fig. 8(d), Fig. 9(d), Fig. 10(d), respectively.

Moreover, the experimental results of the learning rate variation in the modified recurrent Legendre NN are shown in Fig. 15, where the response of the learning rate $\mu_{a}$ of the connection weights in the $125.6 \mathrm{rad} / \mathrm{s}$ (1200rpm) case is shown in Fig. 15(a). The response of the learning rate $\mu_{b}$ of the recurrent weights in the $125.6 \mathrm{rad} / \mathrm{s}$ (1200rpm) case is shown in Fig. 15(b). The response of the learning rate $\mu_{a}$ of the connection weights in the $251.2 \mathrm{rad} / \mathrm{s}$ (2400rpm) case is shown in Fig. 15(c). The response of the learning rate $\mu_{b}$ of the recurrent weights in the 251.2 rad/s (2400rpm) case is shown in Fig. 15(d). The learning rate $\mu_{a}$ variation of the connection weights and the learning rate $\mu_{b}$ variation of the 
TABLE I

Performance Comparisons of CONTROl Systems

\begin{tabular}{|c|c|c|c|c|}
\hline \multirow[b]{2}{*}{ Performance } & \multicolumn{4}{|c|}{ Well-Known PI Controller } \\
\hline & $\begin{array}{|lrr|}125.6 & \mathrm{rad} / \mathrm{s} & (1200 \\
\mathrm{rpm}) & \text { under } & \text { the } \\
\text { lumped } & \text { nonlinear } \\
\text { external } & & \\
\text { disturbances } & \\
\end{array}$ & $\begin{array}{|lrr|}251.2 & \mathrm{rad} / \mathrm{s} & (2400 \\
\mathrm{rpm}) & \text { under } & \text { the } \\
\text { lumped } & \text { nonlinear } \\
\text { external } & & \\
\text { disturbances } & \\
\end{array}$ & $\begin{array}{|lrr|}376.8 & \mathrm{rad} / \mathrm{s} & (3600 \\
\mathrm{rpm}) & \text { under } & \text { the } \\
\text { lumped } & \text { nonlinear } \\
\text { external } & & \\
\text { disturbances } & \\
\end{array}$ & $\begin{array}{l}\text { With adding load and } \\
\text { shedding load under } \\
T_{l}=2 \mathrm{Nm}\left(T_{a}\right)+T_{u n} \\
\text { load } \\
\text { disturbance }\end{array}$ \\
\hline Maximum er & $\begin{array}{l}5.5 \mathrm{rad} / \mathrm{s} \\
(53 \mathrm{rpm}) \\
\end{array}$ & $\begin{array}{l}36.5 \mathrm{rad} / \mathrm{s} \\
(349 \mathrm{rpm}) \\
\end{array}$ & $\begin{array}{c}41 \mathrm{rad} / \mathrm{s} \\
(392 \mathrm{rpm})\end{array}$ & $\begin{array}{c}32 \mathrm{rad} / \mathrm{s} \\
(306 \mathrm{rpm})\end{array}$ \\
\hline RMS error of & $\begin{array}{l}5.0 \mathrm{rad} / \mathrm{s} \\
(48 \mathrm{rpm})\end{array}$ & $\begin{array}{l}6.5 \mathrm{rad} / \mathrm{s} \\
(62 \mathrm{rpm})\end{array}$ & $\begin{array}{l}8.5 \mathrm{rad} / \mathrm{s} \\
(81 \mathrm{rpm})\end{array}$ & $\begin{array}{l}5.5 \mathrm{rad} / \mathrm{s} \\
(53 \mathrm{rpm})\end{array}$ \\
\hline $\begin{array}{r}\text { Contro } \\
\text { and } \mathrm{F}\end{array}$ & \multicolumn{4}{|c|}{ Three-Layer Recurrent NN Control System } \\
\hline Performance & $\mid \begin{array}{lrr}125.6 & \mathrm{rad} / \mathrm{s} & (1200 \\
\mathrm{rpm}) & \text { under } & \text { the } \\
\text { lumped } & \text { nonlinear } \\
\text { external } & & \\
\text { disturbances } & \end{array}$ & $\begin{array}{l}251.2 \mathrm{rad} / \mathrm{s} \quad(2400 \\
\mathrm{rpm}) \quad \text { under the } \\
\text { lumped nonlinear } \\
\text { external } \\
\text { disturbances }\end{array}$ & $\mid \begin{array}{lrr}376.8 & \mathrm{rad} / \mathrm{s} & (3600 \\
\mathrm{rpm}) & \text { under } & \text { the } \\
\text { lumped } & \text { nonlinear } \\
\text { external } & & \\
\text { disturbances } & \end{array}$ & 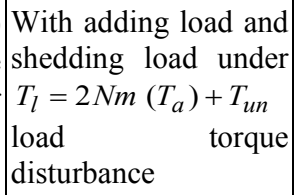 \\
\hline Maxil & $\begin{array}{l}5.5 \mathrm{rad} / \mathrm{s} \\
(53 \mathrm{rpm})\end{array}$ & $\begin{array}{l}11.5 \mathrm{rad} / \mathrm{s} \\
(110 \mathrm{rpm})\end{array}$ & $\begin{array}{c}20 \mathrm{rad} / \mathrm{s} \\
(191 \mathrm{rpm})\end{array}$ & $\begin{array}{c}20 \mathrm{rad} / \mathrm{s} \\
(191 \mathrm{rpm})\end{array}$ \\
\hline RMS error of $e$ & $\begin{array}{l}3.5 \mathrm{rad} / \mathrm{s} \\
(33 \mathrm{rpm})\end{array}$ & $\begin{array}{l}3.5 \mathrm{rad} / \mathrm{s} \\
(33 \mathrm{rpm})\end{array}$ & $\begin{array}{l}3.5 \mathrm{rad} / \mathrm{s} \\
(33 \mathrm{rpm})\end{array}$ & $\begin{array}{l}3.0 \mathrm{rad} / \mathrm{s} \\
(29 \mathrm{rpm})\end{array}$ \\
\hline $\begin{array}{r}\text { Control System } \\
\text { and Four Test }\end{array}$ & \multicolumn{4}{|c|}{ Novel Hybrid Modified Recurrent Legendre NN Control System } \\
\hline Performance & $\begin{array}{|lrr|}125.6 & \mathrm{rad} / \mathrm{s} & (1200 \\
\mathrm{rpm}) & \text { under } & \text { the } \\
\text { lumped } & \text { nonlinear } \\
\text { external } & & \\
\text { disturbances } & \\
\end{array}$ & \begin{tabular}{|l}
$251.2 \mathrm{rad} / \mathrm{s} \quad(2400$ \\
$\mathrm{rpm})$ under the \\
lumped nonlinear \\
external \\
disturbances
\end{tabular} & $\begin{array}{|lrr|}376.8 & \mathrm{rad} / \mathrm{s} & (3600 \\
\mathrm{rpm}) & \text { under } & \text { the } \\
\text { lumped } & \text { nonlinear } \\
\text { external } & & \\
\text { disturbances } & \\
\end{array}$ & $\begin{array}{l}\text { With adding load and } \\
\text { shedding load under } \\
T_{l}=2 \mathrm{Nm}\left(T_{a}\right)+T_{u n} \\
\text { load } \\
\text { disturbance }\end{array}$ \\
\hline Maximum error of $e$ & $\begin{array}{l}4.5 \mathrm{rad} / \mathrm{s} \\
(43 \mathrm{rpm})\end{array}$ & $\begin{array}{l}5.5 \mathrm{rad} / \mathrm{s} \\
(53 \mathrm{rpm})\end{array}$ & $\begin{array}{l}10 \mathrm{rad} / \mathrm{s} \\
(96 \mathrm{rpm})\end{array}$ & $\begin{array}{c}9 \mathrm{rad} / \mathrm{s} \\
(86 \mathrm{rpm})\end{array}$ \\
\hline RMS error of $e$ & $\begin{array}{l}2.0 \mathrm{rad} / \mathrm{s} \\
(19 \mathrm{rpm})\end{array}$ & $\begin{array}{l}2.5 \mathrm{rad} / \mathrm{s} \\
(24 \mathrm{rpm})\end{array}$ & $\begin{array}{l}2.5 \mathrm{rad} / \mathrm{s} \\
(24 \mathrm{rpm})\end{array}$ & $\begin{array}{l}2.0 \mathrm{rad} / \mathrm{s} \\
(19 \mathrm{rpm})\end{array}$ \\
\hline
\end{tabular}

TABLE II

Characteristic Performance Comparisons of Control Systems

\begin{tabular}{|c|c|c|c|}
\hline $\begin{array}{l}\text { Characteristic } \\
\text { Performance }\end{array}$ & Well-Known PI Controller & $\begin{array}{l}\text { Three-Layer Recurrent } \mathrm{NN} \\
\text { Control System }\end{array}$ & $\mid \begin{array}{lrr}\text { Novel Hybrid } & \text { Modified } \\
\text { Recurrent } & \text { Legendre } & \text { NN } \\
\text { Control System } & \end{array}$ \\
\hline Dynamic Response & Slower & Fast & Fastest \\
\hline Load Regulation Capability & $\mathrm{Bad}$ & Good & Best \\
\hline $\begin{array}{l}\text { Convergence } \\
\text { Speed }\end{array}$ & Slow & $\begin{array}{c}\text { Fast } \\
\text { (Fixed Learning Rate) }\end{array}$ & $\begin{array}{c}\text { Fastest } \\
\text { (Vary Learning Rate) }\end{array}$ \\
\hline $\begin{array}{l}\text { Torque Ripple } \\
\text { (Due to V-belt Shaking Friction, } \\
\text { Action friction between Primary } \\
\text { Pulley and Second Pulley) }\end{array}$ & Large & Middle & Small \\
\hline Learning Rate & None & Fixed & $\begin{array}{c}\text { Vary } \\
\text { (Optimal Learning Rate) }\end{array}$ \\
\hline
\end{tabular}


recurrent weights in the $251.2 \mathrm{rad} / \mathrm{s}(1200 \mathrm{rpm})$ case and in the $251.2 \mathrm{rad} / \mathrm{s}$ (2400rpm)case have fast convergences to be bounded from the experimental results.

Finally, the measured rotor speed response under step load torque disturbances is given. The condition under a $T_{l}=2 \mathrm{Nm}\left(T_{a}\right)+T_{u n}$ load torque disturbance with adding a load and shedding a load is tested while using the well-known PI controller, the three-layer recurrent $\mathrm{NN}$ control system and the novel hybrid modified recurrent Legendre $\mathrm{NN}$ control system. The experimental result under a $T_{l}=2 N m\left(T_{a}\right)+T_{u n}$ load torque disturbance with adding a load and shedding a load at the command rotor speed $251.2 \mathrm{rad} / \mathrm{s}(2400 \mathrm{rpm})$ is shown in Figs. 16-18. The experimental result of the measured rotor speed response and measured current in phase $a$ while using the well-known PI controller under a $T_{l}=2 \mathrm{Nm}\left(T_{a}\right)+T_{u n}$ load disturbance with adding a load and shedding a load at 251.2 $\mathrm{rad} / \mathrm{s}$ (2400 rpm) is shown in Fig. 16(a), and the amplified speed error $e_{c}$ response is shown in Fig. 16(b). The experimental results of the measured rotor speed response and the measured current in phase $a$ while using the three-layer recurrent NN control system under a $T_{l}=2 \mathrm{Nm}\left(T_{a}\right)+T_{u n}$ load disturbance with adding a load and shedding a load at $251.2 \mathrm{rad} / \mathrm{s}(2400 \mathrm{rpm})$ is shown in Fig. 17(a), and the amplified speed error $e_{c}$ response is shown in Fig. 17(b).

The experimental result of the measured rotor speed response and the measured current in phase $a$ while using the novel hybrid modified recurrent Legendre NN control system under a $T_{l}=2 N m\left(T_{a}\right)+T_{u n}$ load disturbance with adding a load and shedding a load at 251.2 rad/s (2400 rpm) is shown in Fig. 18(a), and the amplified speed error $e_{c}$ response is shown in Fig. 18(b). From the experimental results, the degenerated responses due to a $T_{l}=2 \mathrm{Nm}\left(T_{a}\right)+T_{u n}$ load disturbance are greatly improved when using the novel hybrid modified recurrent Legendre $\mathrm{NN}$ control system. From the experimental results, it can be seen that the transient response of the novel hybrid modified recurrent Legendre NN control system is better than that of the well-known PI controller and the three-layer recurrent NN control system in terms of load regulation.

Moreover, the novel hybrid modified recurrent Legendre $\mathrm{NN}$ control system has a faster convergence and better load regulation than the three-layer recurrent $\mathrm{NN}$ control system under a $T_{l}=2 \mathrm{Nm}\left(T_{a}\right)+T_{u n}$ load disturbance.

In addition, control performance comparisons of the PI controller, the three-layer recurrent NN control system and then novel hybrid modified recurrent Legendre NN control system are summarized in Table I. They are shown for the experimental results under the four test cases. In Table I, the novel hybrid modified recurrent Legendre NN control system results in a smaller tracking speed error with respect to the PI controller and the three-layer recurrent $\mathrm{NN}$ control system. According to the tabulated measurements, the proposed novel hybrid modified recurrent Legendre NN control system yields superior control performance when compared with the PI controller and the three-layer recurrent $\mathrm{NN}$ control system. Furthermore, characteristic performance comparisons of the PI controller, the three-layer recurrent $\mathrm{NN}$ control system and the novel hybrid modified recurrent Legendre $\mathrm{NN}$ control system are summarized in Table II for the experimental results. In Table II, it can be seen that the various performances of the novel hybrid modified recurrent Legendre NN control system are superior to those of the PI controller and the three-layer recurrent $\mathrm{NN}$ control system.

\section{CONCLUSIONS}

A novel hybrid modified recurrent Legendre NN control system has been successfully developed in this paper to control V-belt CVT driven electric scooters using a PMSM servo drive system with robust control characteristics. The adopted modified recurrent Legendre NN has a self-feedback connection in the hidden layer and a recurrent connection between the output layer and the input layer. It is more powerful than the three-layer recurrent $\mathrm{NN}$ for dealing with time-varying and nonlinear dynamical systems. Moreover, in order to improve the ability in terms of identifying high order systems and the convergence speed of the parameters, a modified recurrent Legendre $\mathrm{NN}$ with two optimal learning rates is also proposed in this paper. It has been proved through experimental results that the modified recurrent Legendre $\mathrm{NN}$ has more advantages than the three-layer recurrent $\mathrm{NN}$ with the sigmoid activation function, including better performance, higher accuracy, increased dynamic robustness and faster transient performance.

The main contributions of this paper are as follows as: (1) a dynamic models of a V-belt CVT driven electric scooter with unknown nonlinear and time-varying characteristics using a PMSM servo drive system was successful derived; (2) a novel hybrid modified recurrent Legendre NN control system for V-belt CVT driven electric scooters using a PMSM servo drive system under the occurrence of the variations in the rotor inertia and load torque disturbance was successful applied to enhance robustness; (3) the on-line parameters tuning methodology of the modified recurrent Legendre NN and the estimation law of the remunerated controller using the Lyapunov stability theorem were successful derived; (4) two optimal learning rates for the connective weight and recurrent weight of the modified recurrent Legendre NN according to the discrete-type Lyapunov function were successful derived in order to speedup convergence; (5) a novel hybrid modified recurrent 
Legendre NN control system, which has a fast convergence ability and fast capture in terms of the system's nonlinear and time-varying behaviors, is successful developed; (6) the proposed novel hybrid modified recurrent Legendre $\mathrm{NN}$ control system has a lower torque ripple than the well-known PI controller and the three-layer recurrent $\mathrm{NN}$ control systems. Therefore, the control performance of the proposed hybrid modified recurrent Legendre NN control system is more suitable than the well-known PI controller and the three-layer recurrent NN control systems for V-belt CVT driven electric scooters using a PMSM servo drive system.

\section{REFERENCES}

[1] I. Takahashi and T. Noguchi, "A new quick-response and high efficiency control strategy of an induction motor," IEEE Trans. Ind. Appl., Vol. 22, No. 5, pp. 820-827, Sep. 1986.

[2] T. G. Habetler, F. Profumo, M. Pastorelli, and L. M. Tolbert, "Direct torque control of induction machines using space vector modulation," IEEE Trans. Ind. Appl., Vol. 28, No. 5, pp. 1045-1053, Oct. 1992.

[3] L. Zhong, M. F. Rahman, W. Y. Hu, and K. W. Lim, "Analysis of direct torque control in permanent magnet synchronous motor drives," IEEE Trans. Power Electron., Vol. 12, No. 3, pp. 528-536, May 1997.

[4] L. Zhong, M. F. Rahman, W. Y. Hu, K. W. Lim, and M. A. Rahman, "A direct torque controller for permanent magnet synchronous motor drives," IEEE Trans. Energy Convers., Vol. 14, No. 3 pp. 637-642, Sep. 1999.

[5] D. W. Novotny and T. A. Lipo, Vector Control and Dynamics of AC Drives, Oxford University Press, 1996.

[6] R. Krishnan, Electric Motor Drives: Modeling, Analysis, and Control, Prentice Hall, 2001.

[7] F. J. Lin, "Real-time IP position controller design with torque feedforward control for PM synchronous motor," IEEE Trans. Ind. Electron., Vol. 4, No. 3, pp. 398-407, Jun. 1997.

[8] S. Haykin, Neural Networks, Maxwell Macmillan, pp. 124-128, 1994.

[9] M. N. Eskander, "Minimization of losses in permanent magnet synchronous motors using neural network," Journal of Power Electronics, Vol. 2, No. 3, pp 220-229, Jul. 2002.

[10] P. S. Sastry, G. Santharam, and K. P. Unnikrishnan, "Memory neural networks for identification and control of dynamical systems," IEEE Trans. Neural Netw., Vol. 5, No. 2, pp. 306-319,Mar. 1994.

[11] J. S. Ko, J. S. Choi, and D. H. Chung, "Maximum torque control of an IPMSM drive using an adaptive learning fuzzy-neural network," Journal of Power Electronics, Vol. 12, No. 3, pp. 468-476, May 2012.

[12] Y. H. Pao, Adaptive Pattern Recognition and Neural Networks, Addison-Wesley, 1989.

[13] Y. H. Pao and S. M. Philips, "The functional link net and learning optimal control," Neurocomputing, Vol. 9, No. 2, pp. 149-164, Oct. 1995.

[14] J. C. Patra, R. N. Pal, B. N. Chatterji, and G. Panda, "Identification of nonlinear dynamic systems using functional link artificial neural networks," IEEE Trans. Syst.,
Man, Cybern. B, Cybern.,Vol. 29, No. 2, pp. 254-262, Apr. 1999.

[15] S. Dehuriand and S. B. Cho, "A comprehensive survey on functional link neural networks and an adaptive PSOBP learning for CFLNN," Neural Computing and Applications, Vol. 19, No. 2, pp 187-205, Mar. 2010.

[16] S. S. Yang and C. S. Tseng, "An orthogonal neural network for function approximation," IEEE Trans. Syst., Man, Cybern. B, Cybern., Vol. 26, No. 5, pp. 779-785, Oct. 1996.

[17] J. C. Patra, W. C. Chin, P. K. Meher, and G. Chakraborty, "Legendre-FLANN-based nonlinear channel equalization in wireless communication systems," in Proc. IEEE Int. Conf. Systems, Man, Cybernetics, pp. 1826-1831, 2008.

[18] J. C. Patra, P. K. Meher and G. Chakraborty, "Nonlinear channel equalization for wireless communication systems using Legendre neural networks," Signal Processing, Vol. 89, No. 12, pp. 2251-2262, Dec. 2009.

[19] J. C. Patra and C. Bornand, "Nonlinear dynamic system identification using Legendre neural network," in Proc. Int. Joint Conf. Neural Networks, pp. 1-7, 2010.

[20] F. Liu and J. Wang, "Fluctuation prediction of stock market index by Legendre neural network with random time strength function," Neurocomputing, Vol. 83, pp. 12-21, Apr. 2012.

[21] K. K. Das and J. K. Satapathy, "Novel algorithms based on Legendre neural network for nonlinear active noise control with nonlinear secondary path," Int. J. Computer Science and Information Technology, Vol. 3, No. 5, pp. 5036-5039, 2012.

[22] R. K. Madyastha and B. Aazhang, "An algorithm for Training multilayer perceptrons for data classification and function interpolation," IEEE Trans. Circuits Systems-I, Vol. 41, No. 12, pp. 866-875, Dec. 1994.

[23] T. W. S. Chow and Y. Fang, "A recurrent neural-network-based real-time learning control strategy applying to nonlinear systems with unknown dynamics," IEEE Trans. Ind. Electron., Vol. 45,No. 1, pp. 151-161, Feb. 1998.

[24] X. D. Li, J. K. L. Ho, and T. W. S. Chow, “Approximation of dynamical time-variant systems by continuous-time recurrent neural networks," IEEE Trans. Circuits Syst. II, Exp. Briefs, Vol. 52, No. 10, pp.656-660, Oct. 2005.

[25] C. H. Lu and C. C. Tsai, "Adaptive predictive control with recurrent neural network for industrial processes: an application to temperature control of a variable-frequency oil-cooling machine," IEEE Trans. Ind. Electron., Vol. 55, No. 3, pp. 1366-1375, Mar. 2008.

[26] A. F. Payam, M. N. Hashemnia, and J. Faiz, "Robust DTC control of doubly-fed induction machines based on input-output feedback linearization using recurrent neural networks," Journal of Power Electronics, Vol. 11, No. 5, pp. 719-725, Sep. 2011.

[27] J. L. Elman, "Finding structure in time," Cognitive Science, Vol. 14, No. 2, pp. 179-211, Apr.-Jun.1990.

[28] X. Y. Yang, D. P. Xu, X. J. Han, and H. N. Zhou, "Predictive functional control with modified Elman neural network for reheated steam temperature," in IEEE Int. Conf. Machine Learning Cybernetics, pp. 4699-4703, Aug. 2005.

[29] C. H. Lin, "Novel modified Elman neural network control for PMSG system based on wind turbine emulator," Mathematical Problems in Engineering, Vol. 2013, Article ID 753756, 15 pages, May 2013.

[30] C. H. Lin, "Recurrent modified Elman neural network control of PM synchronous generator system using wind turbine emulator of PM synchronous servo motor drive," Int. 
J. Electrical Power and Energy Systems, Vol. 52, pp. 143-160, Nov. 2013.

[31] S. J. Yoo, J. B. Park, and Y. H. Choi, "Stable predictive control of Chaotic systems using self-recurrent wavelet neural network," Int. J. Automatic Control Systems, Vol. 3, No.1, pp. 43-55, Feb. 2005.

[32] C. H. Lu, "Design and application of stable predictive controller using recurrent wavelet neural networks," IEEE Trans. Ind. Electron., Vol. 56, No. 9, 3733-3742, Sep. 2009.

[33] C. H. Lin, "Hybrid recurrent wavelet neural network control of PMSM servo-drive system for electric scooter," Int. J. Automatic Control Systems, Vol. 12, No. 1, pp. 177-187, Feb. 2014.

[34] C. H. Lin and C. P. Lin, "The hybrid RFNN control for a PMSM drive system using rotor flux estimator," Int. J. Power Electronics, Vol.4, No. 1, pp. 33-48, 2012.

[35] C. H. Lin, P. H. Chiang, C. S. Tseng, Y. L. Lin, and M. Y. Lee, "Hybrid recurrent fuzzy neural network control for permanent magnet synchronous motor applied in electric scooter," in 6th Int. Power Electronics Conf., pp. 1371-1376, 2010.

[36] C. Y. Tseng, L. W. Chen, Y. T. Lin, and J. Y. Li, "A hybrid dynamic simulation model for urban scooters with a mechanical-type CVT," in IEEE Int. Conf. Automation and Logistics, pp. 519-519, 2008.

[37] C. Y. Tseng, Y. F. Lue, Y. T. Lin, J. C. Siao, C. H. Tsai, and L. M. Fu, "Dynamic simulation model for hybrid electric scooters," in IEEE Int. Symp. Industrial Electronics, pp. 1464-1469, 2009.

[38] K. J. Astrom and T. Hagglund, PID Controller: Theory, Design, and Tuning, Instrument Society of America, 1995.
[39] T. Hagglund and K. J. Astrom, "Revisiting the ZieglerNichols tuning rules for PI control," Asian J. Control, Vol. 4, No. 4, pp. 364-380, Dec. 2002.

[40] T. Hagglund and K. J. Astrom, "Revisiting the ZieglerNichols tuning rules for PI control - part II: the frequency response method," Asian J. Control, Vol. 6, No. 4, pp. 469-482, Dec. 2004.

[41] J. J. E. Slotine and W. Li, Applied Nonlinear Control, Prentice Hall, 1991.

[42] K. J. Astrom and B. Wittenmark, Adaptive Control, Addison-Wesley, 1995.

[43] C. C. $\mathrm{Ku}$ and K. Y. Lee, "Diagonal recurrent neural networks for dynamic system control," IEEE Trans. Neural Netw., Vol. 6, No. 1, pp. 144-156, Jan. 1995.

[44] F. L. Lewis, J. Campos, and R. Selmic, Neuro-Fuzzy Control of Industrial Systems with Actuator Nonlinearities, SIAM Frontiers in Applied Mathematics, 2002.

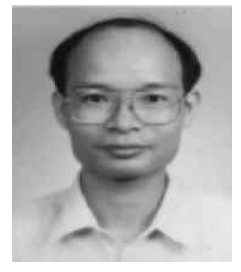

Chih-Hong Lin was born in Taichung, Taiwan, R.O.C. He received his B.S. and M.S degrees in Electrical Engineering from the National Taiwan University of Science and Technology, Taipei, Taiwan, R.O.C., in 1989 and 1991, respectively. He received his Ph.D. degree in Electrical Engineering from Chung Yuan Christian University, Chung Li, Taiwan, R.O.C.,in 2001.He is currently an Associate Professor in the Department of Electrical Engineering, National United University, Miao Li, Taiwan, R.O.C. His current research interests include power electronics, motor servo drives and intelligent control. 